\title{
Assessing users` performance to sustain off-grid renewable energy systems: The capacity and willingness approach
}

\author{
Hong G.W., Abe, N., Baclay, M., and Arciaga, L. \\ by \\ George William HONG \\ (Corresponding Author) \\ International Development Engineering Department (IDE) \\ Tokyo Institute of Technology \\ 2-12-1-I4-4, Ookayama, Meguro-ku, Tokyo, Japan, 152-8550 \\ Email: william.hong@ruralenergy.org \\ Phone/Fax: +81-3-5734-3797 \\ Naoya ABE \\ International Development Engineering Department (IDE) \\ Tokyo Institute of Technology \\ 2-12-1-I4-4, Ookayama, Meguro-ku, Tokyo, Japan, 152-8550 \\ Email: nabe@ide.titech.ac.jp \\ Phone/Fax: +81-3-5734-3797

\section{Magdaleno BACLAY Jr.} \\ Solar Energy Research \\ Ruralenergy.org \\ Email: jun.baclay@ruralenergy.org

\section{Lourdes ARCIAGA} \\ Energy Resource Development and Utilization Division \\ Philippine Department of Energy \\ Email: louarciaga@yahoo.com
}




\begin{abstract}
This paper investigates the sustainability of off-grid renewable energy systems (RES) installed in rural communities. Through a solar home system (SHS) case project in Alumar Island, Philippines, the performance of users to sustain their systems were assessed using a novel approach proposed by the authors: the capacity and willingness approach. This approach was an adaptation to advancements in human development theory - the paradigm shift from the traditional resources approach to the capabilities approach, as proposed by A.Sen. The actual financial and technical performances of users were predicted using ordered logit regression analysis. It was found that financial capacity attributes, e.g., income and expenses, were prominent in explaining financial performance; knowhow-related attributes, e.g., education, were prominent in explaining technical performance; and willingness-related attributes, i.e., willingness to pay, explained both financial and technical performance. The findings aim to provide developers and communities with better strategies for beneficiary scoping, technology selection, and capacity development.
\end{abstract}

\title{
Keywords:
}

off-grid rural electrification, sustainability assessment, renewable energy systems, user capacity, willingness to sustain, ordered logit analysis 


\section{Introduction and Objective of the Study}

Efforts have been made to improve the sustainability of renewable energy systems (RES) in rural settings by focusing on important aspects such as using appropriate technologies and financial mechanisms that cater to specific users` needs and capacities. According to the World Bank, determining the capacity of users and their willingness to pay are essential aspects in the technology selection process of off-grid projects. [1] The challenge, however, lies in properly defining users` capacity and willingness. There are difficulties in interpreting information about the users and communities amidst the limited time and budget constraints of most development projects. There are perceived merits in determining how limited information about users can be used to characterize their capacities and enable developers to effectively assess and foresee sustainability.

This study proposed a methodology to assess the relevance of capacity and willingness of users to the sustainability of RES. The objective is to predict or estimate the sustainability performance of users basing on users`capacity and willingness attributes. The study focused on users`attributes which relate to the financial and technical performance in sustaining their power supply system. For this case, a solar home system (SHS) project in a rural community setting, particularly in Alumar Island, Bohol, Philippines, was investigated. Having reliable users' performance foresight was thought to improve the process of planning and designing appropriate systems for rural electrification projects using RES.

\section{Off-Grid RES and Sustainability}

\subsection{Problem Setting}

Developing a sustainable power project requires a good understanding of not only the technology but also the community and recipient users. According to World Bank guidelines for off-grid electrification projects, calculating tariff roughly commensurate to the consumer's ability and willingness to pay is important for the viability of off-grid services. [1] Conducting detailed investigations, however, are not always feasible due to time and cost constraints. This is especially evident for developing countries, like the Philippines, with many rural areas simultaneously needing attention yet having limited resources, i.e., time, budget, and manpower, to develop such projects.

With resource limitations, developers resort to using easily accessible, simple, and general information about the community and users to design the projects, usually through rapid rural appraisals (RRA). [2] Using such simplified data poses a challenge in processing limited information to meet the complex needs of a power project. To pursue 
sustainability, it is essential to adopt an effective methodology to characterize the capacity of users to sustain their systems.

\subsection{Defining Sustainability, Capacity, and Willingness}

Sustainable development has taken its globally recognized definition from the United Nations` 1987 Brundtland report called "Our Common Future”. [3] This investigation adopts a specific definition of sustainability: the capacity of a system to maintain output at a level approximately equal to or greater than its historic average. [4] In this regard, we refer to the system users as the instruments that have the capacity to maintain and sustain a certain power system.

Capacity is defined as the ability of individuals, institutions, and societies to perform functions, solve problems, and set and achieve objectives in a sustainable manner. [5] Since capacity is quite multi-dimensional we narrow down our scope to describe a certain facet of capacity: the capacity of a user to sustain a particular RES (SHS) system through time as measured by the user`s ability to pay the financial requirements and perform the technical requirements of the system. For rural RES, the financial and technical aspects of projects are two of the most common sources of problems that affect the sustainability of such projects.

While user capacities to sustain the systems vary, it may not always be the case that those with good capability will have the same high interest in sustaining the system. Even if some users are capable they may still be unable and disinterested to perform the necessary actions, evidently leading to a failed or unsustainable project. [6] [7] [8] This occurrence leads developers to discuss another dimension of RES projects sustainability that we refer to as the users` willingness to sustain.

In this study, we define a user's willingness to sustain as the intention or readiness of the user to sustain a particular energy supply system through time. This can be measured by the amount of resources/efforts/utility a person is willing to exchange to sustain the system. Willingness as a concept is not new. Quite related, the term willingness to pay has since been used as a tool to approximate the value of certain non-market goods according to the perceptions and intentions of users and stakeholders. [9] Willingness to sustain, however, does not aim to valuate in monetary terms but rather to measure the readiness of an individual to achieve a certain goal, e.g., paying for electricity.

While capacity deals with abilities and willingness deals with intention or readiness, it may not be as easy to interpret, much less quantify, these qualities in a person. In this study, it was postulated that these qualities are manifested in certain user attributes which are more obvious and measurable. It was inferred that distinguishing capacity from 
willingness and ability from intention, can improve a developer`s understanding of the limited information about users in relation to project sustainability.

\subsection{Case Study of a Solar Home System in a Rural Island in the Philippines}

In order to further understand the concepts of capacity and willingness to sustain, a rural island case scenario where an SHS project is in operation was investigated. Solar home systems (SHS) are compact photovoltaic (PV) generation systems composed of only a few key components: PV panel, charge controller, and a battery. These compact systems can generate power for a typical rural household and are especially applicable when households are situated far from each other and far from the main electricity grid. The system utilizes the solar PV modules to charge the batteries during daytime to power light, radios, and cellphone chargers well into the night. These types of systems have been used to power millions of households in Asia, Africa, and many more developing areas. [1]

Fig. $1<$ Here $>$

Source: author modifications from [10]

This paper investigated a project in Alumar Island, a small rural island located 3 kilometers from the main island of Bohol, Philippines. The island has a population of about 800 people (170 households) with fishing and seaweeds farming as the main means of livelihood. While rich with aquatic resources, electricity and basic lighting has been the main challenge for the island residents.

In year 2008, the Philippine Department of Energy (DOE), Japan International Cooperation Agency (JICA), and the Alumar local government unit (LGU) came into partnership to provide 50 households in the community with their own solar home systems (SHS). Each SHS unit was composed of a solar panel (55 to $75 \mathrm{Wp}$ ), a charge controller, a lead-acid battery, and a few lighting appliances, i.e., 3 units of 11-Watt compact fluorescent lamps. While the units were provided on a first-come-first-served basis, recipients were required to pay a participation fee of $\mathrm{PhP} 1,500$ to avail of the system. ( $1 \mathrm{PhP}=0.024 \mathrm{USD})$ This was done to sort out those who were indeed willing and determined to avail of a system. Fig. 1 shows a household with an installed SHS in Alumar Island.

The individual households are required to pay a monthly maintenance fee of $200 \mathrm{PhP}$ (5 USD) to the community cooperative, the Barangay Alumar Power Association (BAPA). The funds are allotted for technical maintenance support and a portion goes to a 
savings fund for battery and charge controller replacement. All users were required to undergo a workshop prior to installation to learn the simple operations and maintenance tasks necessary for their own systems: cleaning the battery and charge controller, checking for battery water level and refilling if necessary; safety checking for wirings and; and regulating appliance usage.

In a sustainability perspective, the proper functioning of the system relies heavily on the financial and technical performance of the users. If monthly dues are paid properly, the batteries and charge controllers can be replaced when the components reach end-of-life. If proper basic operations and maintenance are performed correctly, the efficiency and life-span of the parts would serve well for the designed years of service.

The project started in year 2008 and it has since become evident that some of the users were not in a good position to maintain the SHS for the long run. Some users were delinquent in paying monthly dues while others neglected the daily maintenance tasks. Given the fairly well-documented financial performance of users and the identifiable conditions of differences in technical performance of users, this particular project case in Alumar served as a good scenario to further investigate the tendencies of users in sustaining RES systems in rural settings.

\section{Methodology and theoretical framework}

\subsection{Methodology}

An explanatory research approach was used to define a new perspective and theory in understanding sustainability of rural RES projects. A case investigation was conducted for the SHS project in Alumar Island, Philippines. The methodology of the investigation and model development process are shown in Fig. 2.

The theoretical framework of capacity and willingness assessment was first discused using theories from human development. The framework was then applied to the island case. Two surveys were conducted: (a) a survey of users`attributes and financial performance; and (b) a technical assessment to determine and score the users` technical performance. The Alumar SHS users, made p of a total of 50 households, were surveyed, in local Visayan dialect, relating to their demographics and electricity usage. The surveys were done in coordination with the BAPA and experts from DOE - Visayas field office.

After data collection, the users`attributes which relate to the capacity and willingness of users were empirically classified. Based on the theoretical framework, performance models were then developed using models of the capacity-related and 
willingness-related attributes. The ordered logit regression model was found appropriate to predict or estimate user performance. Ordered logit uses maximum likelihood estimation of probabilities of performance scores. Since ordered logit uses categorical data, a categorization step was applied prior to model development. Sensitivity analyses were also conducted. The investigation then outlined the practical and policy implications.

\section{Fig. 2 <Here>}

Source: author

\subsection{Theoretical framework and Application}

The sustainability framework proposed in this investigation takes root from theories of human development, which has inspired concepts for economic development. [11] One traditional approach in measuring human development and an individual's quality of life has been through the resources approach. This approach used monetary indicators, e.g., income and consumption, and non-monetary indicators, e.g., education, health, water, and electricity, based on resources. [12] It has been argued, however, that measuring development or welfare based on resources alone did not comprehensively consider other functions, as resources were merely instruments to other objectives. This eventually led to the development of the capabilities approach in measuring quality of life, as proposed by Amartya Sen. [13] The capabilities approach argues that quality of life should be conceived and measured in terms of capabilities instead of resources or utility. [14] This concept tried to distinguish the difference between having resources and being able to use these resources to achieve a goal.

\section{Fig. 3 <Here>}

Source: author

From Sen`s capabilities approach to understanding human welfare, the author adopts a similar paradigm shift to explain RES sustainability and user performance. The proposed concept is termed as the capacity and willingness approach. This approach mainly postulates that in order to better estimate sustainability performance, both the capacity and willingness of users should be considered instead of the resources available. It is, however, recognized that resources are important attributes which are measurable and can be used to represent and indicate the capacities of users.

The theoretical framework shown in Fig. 3 differentiates the resources approach from the capacity and willingness approach leading to sustainability. For this 
investigation, sustainability is measured by the performance of users, specifically financial and technical performance. Performance has been viewed as key outputs of capacity and capacity development, linking it to sustainability [15] [17] [18].

The traditional resources approach depicts the technical and financial feasibility and sustainability of projects based on the resources available to the users. Relating with the Alumar Case, a resources approach would use indicators such as user`s income and expenditures to indicate how a user has access to the resources to sustain the system. As argued by A.Sen, this perspective has certain limitations in explaining how users are able to convert the resources into achievements. [16]

The capacity and willingness approach shifts the paradigm to perceive user performance as a function of capacity. Current development theory suggests that performance is affected by both the capacity or abilities of an individual and the external environment. [18] Both factors are aggregated as the capacity component to the model. The approach further proposes that performance is not only affected by capacity but also by the intention or willingness of the users to perform. Thus, a willingness component is distinctly added to the model. As capacity and willingness are quite intangible, making it difficult to measure, it is postulated that these abilities and intentions manifest in specific user attributes which are measurable.

\section{Fig. 4 <Here>}

Source: author

The model can be understood and tested when adopted to the Alumar Case, shown in Fig. 4. The user attributes are used as proxies for the capacity and willingness components to explain performance and sustainability. Sustainability of RES was defined by users` financial and technical performance. The financial dimension is defined by how users are able to pay their monthly payments to keep using their SHS units. On the other hand, the technical dimension is defined by how users are able to operate and maintain the physical parts of the SHS, i.e., batteries, charge controller, and loads, to be in workable condition.

Typical user attributes were determined and classified into capacity-related and willingness-related attributes. For financial capacity, for example, the gross income may indicate a user's ability to earn and be able to pay for the costs of the system. For technical capacity, the education level would indicate a user`s ability to comprehend and perform the necessary maintenance tasks. The willingness components of the model seeks to determine the user's readiness and intention to pay for the financial needs and perform the 
technical tasks. Willingness to pay and the perceived importance of electricity are some attributes that may indicate readiness and intention.

\subsection{Adopting Ordered Logit Regression Analysis (Ologit)}

Applying the proposed approach, quantifiable user attributes are used as proxies for capacity and willingness of an individual to predict the performance of an individual. In this study, the ordered logit (Ologit) model, an extension of the logit model capable of handling multiple categorical data, was found appropriate to estimate the performance of users. A reference literature shows the application of Ologit using the resources approach. In the study by [21], the electricity demand of households was estimated using household resources such as income, appliances, the number of family members. To differentiate the approach in this study, we extend the application of Ologit models to utilize the capacity and willingness attributes of households to explain sustainability performance. The following explain the process of applying Ologit.

For categorical variables with a meaningful sequential order, an ordered logit or Ologit regression analysis can be used. Ologit begins by categorizing the dependent variable into $k$ categories with values $i$ (e.g. $i_{1}=$ poor, $i_{2}=$ average, and $i_{3}=$ good). The probability of a given observation $y$ to have a categorical value $i$ is calculated as Eq. 1 . Ologit estimates the log-odds probability $S$ of the predicted variable to a linear relationship of the predictor variables $x$ using the maximum-likelihood principle. The linear prediction of the log-odds probability is depicted as Eq. 2. The probability that an observation $\left(S_{j}+u_{j}\right)$ lies between cut-points $k$ can be computed through the equations in Eq. 3.

\section{Eq. 1}

$$
\operatorname{Pr}\left(y_{j}=i\right)=\operatorname{Pr}\left(k_{i-1}<S_{j}+u \leq k_{i}\right)
$$

\section{Eq. 2}

$$
S_{j}=x_{1 j} \beta_{1}+x_{2 j} \beta_{2}+\cdots+x_{m j} \beta_{m}
$$

\section{Eq. 3}

$$
\operatorname{Pr}\left(S_{j}+u_{j}<k\right)=1 /\left(1+e^{S_{j}-k}\right)
$$


The linear prediction produces coefficients $(\beta)$ in log-odd units. The significance of the predictors to the model is depicted by the $z$ statistics and $P$ value. The overall significance of the model is assessed by the chi-square value and the pseudo- $R^{2}$. [22] [23] For the investigation, the software STATA was used to compute Ologit estimations. [19] Further details, applications, and explanations of the process of Ologit can be acquired through the following references. [24] [21]

The following introduces the process for model and variable selection adopted for the study: (1) initially introduce several predictor variables and check for significance of the overall model $\left(\mathrm{chi}^{2}\right)$ and per variable (P values) to the $90 \%$ or $95 \%$ confidence interval (CI); (2) systematically and empirically eliminate the variables which are not significant. (3) accept the model using several criteria: a) overall model significance is acceptable at $95 \% \mathrm{CI}, \mathrm{b})$ pseudo- $\mathrm{R}^{2}$ is reasonable, c) majority of the variables are significant at least to the $90 \% \mathrm{CI}$, and d) overall predictive ability is high. The ideal maximum number of explanatory variables to retain would be 1 variable per 10 observations. [25] For this case, with 47 observations, 5 retained explanatory variables were considered acceptable.

Model testing was performed by calculating the percentage of correctly predicted scores from the actual performance scores. Model accuracy was computed as \% Accuracy = correctly predicted scores (users) / total number of users. Among several models, a single most admissible model was selected for each of the 2 and 3 category scoring based on the model accuracy.

Sensitivity analysis was conducted to check the marginal effects on probabilities. Marginal effects, denoted as $d s / d x$, measures instantaneous rate of change of probabilities. [25] This indicates how a particular variable, when increased or decreased while holding all other variables constant at their means, would affect the probability of a particular score. Figures 5 to 10 depict the sensitivity analyses of variables. The abscissa displays the range of values for the variable while the ordinate displays the probability value of the variable. More information on understanding such graphs can be found in [19] and [25].

4. Model Development and Analysis

4.1 Data collection

The Alumar SHS project has a total of 50 SHS users, 47 of which were noted to be 
applicable for the investigation. Individual household surveys were conducted to collect basic information about the users, as shown in Table 1. Respondents were limited to be the household head or the spouse to represent the household.

For the actual financial performance of users (A_Financial), project reports and documentations dating back to the start of the project in 2008 were compiled and analyzed. Financial performance can be measured by the completeness of payments a person has made through the course of time to maintain the system. A_Financial is measured in percent or ratio of the total number of monthly payments made divided by the total months, i.e., 39 months, payments were required: $A \_$Financial score $=$total payments made / total payments required.

For the actual technical performance of users (A_Technical), a special scoring system was developed for the purpose, as shown in Table 2. The objective was to be able to score the condition of the solar home system in a particular household basing on criteria which relate to the function-ability of the system. The scoring system was developed in consultation with experts from the DOE and the local technicians who maintained the SHSs.

For financial items, GrossIncome, NetIncome, FoodExp, WaterExp, EducExp, ElecExp, PrePVExp, HealthExp, and TransExp were approximated for a typical month. For further analytical purposes, the percentages of the expenses vs. the GrossIncome were also computed. These percentage values are noted as follows: $P_{-}$FoodExp, $P_{-}$WaterExp, $P \_$EducExp, P_ElecExp, P_PrePVExp, P_HealthExp, and P_TransExp.

The level of education (Education) of the household head was considered and scored for the following categories: $1=$ elementary non-graduate; $2=$ elementary graduate; $3=$ high school non-graduate; $4=$ high school graduate; and $5=$ college or vocational school level.

For hours of electricity use (ElecUse), typical daily usage were categorized as follows: $1=$ less than 3 hours; $2=3$ to 8 hours; and $3=$ more than 8 hours.

For the self-rating of SHS system knowhow (SelfRating), respondents were asked to score their relative confidence of their knowledge about the SHS. The ratings were in a 1 to 5 scale: $1=$ not knowledgeable to $5=$ very knowledgeable.

For willingness of users to pay (Will_MaxPay), the respondents were asked the following question: What is the maximum monthly amount (in $P h P$ ) are you willing to pay for the SHS system? As secondary data, the percentage of Will_MaxPay vs. the GrossIncome was computed as $P_{-}$WillMaxPay.

For willingness of users to maintain the system (Will_Maintain), the users were asked the following question: How willing are you to perform/follow the necessary 
actions/procedures to properly maintain the SHS system? The Score ranged from 1 if not willing to 5 if very willing.

For the ease of payment of SHS (EasePay), respondents were asked to score their relative comfort or level of ease in paying the monthly maintenance cost of the system. The ratings were done in a 1 to 5 scale from $1=$ not easy at all to $5=$ very easy.

For the level of electricity importance (ElectImp), respondents were asked to score the relative level of importance of particular household needs, such as food, water, house, electricity, transportation, and health. The top 5 items were ranked in a 1 to 5 scale from 1 $=$ least important to $5=$ most important.

\section{Table $1<$ Here >}

Source: Survey 2011b and Survey 2012

Table $2<$ Here $>$

Source: author, with expert opinion from DOE-VFO and BAPA staff

\subsection{Classification of Variables}

After collecting and checking the data from each household, the variables were classified as whether they were capacity-related or willingness-related based on empirical judgment. Variables were further sub-classified into financial or technical (know-how) related variables. The variables are shown in Table 3 .

\section{Table 3 <Here>}

Source: author

\subsection{Categorization Through Cluster Analysis}

The Ologit model requires predicted variables to be categorical in form. For the performance scores, $A \_$Financial is a continuous variable while $A \_T e c h n i c a l$ takes on integer values. To meet the Ologit model requirements, both variables were systematically categorized into meaningful scores, specifically, into 2 and 3 categories which can indicate the user performance to be "poor and good" or "poor, average, and good", respectively. The categorization step was done through cluster analysis, an exploratory data-analysis technique used to categorize data into groups depending on their similarities or dissimilarities. The study adopted the agglomerative hierarchical clustering method with complete-linkage. The software STATA was used to perform the 
cluster analyses. [19] [20]

\subsubsection{Financial Performance Cluster Analysis}

From the cluster analysis, the A_Financial scores were meaningfully clustered into 2-category and 3-category scorings. The 2-category cluster, named C_2_Financial, distinguished poor from good performers. The 3-category cluster, named $C_{-}$3_Financial, identified poor, average, and good performers. In order to conform to the Ologit model which uses numerical variables for explained variables, the performance categories need to be relabeled with numerical designations. For $C \_2 \_$Financial, the good and poor performers were labeled as Score 1 and Score 2, respectively as seen in Table 4. For C_3_Financial, the categories were labeled as Score 1, Score 2, and Score 3, as seen in Table 5.

Table 4 <Here>

Source: author, from Survey 2011b, Survey 2012 and Cluster Analysis

Table 5 <Here>

Source: author, from Survey 2011b, Survey 2012 and Cluster Analysis

\subsubsection{Technical Performance Cluster Analysis}

From the cluster analysis, the $A \_T e c h n i n c a l$ scores, were meaningfully clustered into 2-category and 3-category scorings. The 2-category cluster, named C_2_Technical, identified poor and good performers. The 3-category cluster, named C_3_Technical, identified poor, average, and good performers. To conform to the Ologit model, performance scores were relabeled numerically. For C_2_Technical, the good and poor performers were labeled as Score 1 and Score 2, respectively as seen in Table 6. For C_3_Technical, the categories were labeled as Score 1, Score 2, and Score 3, as seen in Table 7.

\section{Table 6 <Here>}

Source: author, from Survey 2011b, Survey 2012 and Cluster Analysis

Table 7 <Here>

Source: author, from Survey 2011b, Survey 2012 and Cluster Analysis

\subsection{Ordered Logit Model Development and Testing}




\subsubsection{Financial Performance Estimation Using Ologit}

By applying Ologit analysis, the categorized A_Financial scores were estimated. Models were developed for both the 2-category score and the 3-category scores. The presented models were considered to be the most admissible models developed using the criteria and process described for Ologit modeling.

\subsubsection{Model for 2-category Financial Performance}

The model developed for the 2-category financial performance (C_2_Financial) is shown in Table 8 . The model chi $^{2}$ and pseudo- $\mathrm{R}^{2}$ were found acceptable with an overall prediction accuracy of $85 \%$. Results in Table 9 show how 6 out of 12 poor performers and 34 out of 35 good performers were correctly identified. There were 4 significant variables retained: WaterExp, TransExp, PrePVExp, and EasePay.

TransExp was found to have a negative coefficient. This behavior we attribute to a cost competition phenomenon with electricity. We postulate that household expenses, in general, compete with the availability of funds to pay for the PV system. Travelling to the nearby islands and trading their catch is an essential part of livelihood. TransExp indicates a necessary expense, which competes directly with funds available for other expenses such as the SHS. Furthermore, this component can be seen as an effect of the external environment where high costs in transportation expenses can hamper a person`s financial capacity.

WaterExp was found to have a positive coefficient. At first it seems contrary to our hypothesis that expenses would affect financial capacity negatively. Though water is a daily necessity, households may be able to get it for a minimal price through rain water collection or from ground water wells. Paying for better quality and more expensive water on the other hand may be considered a luxury rather than a necessity or a financial burden. This may show that WaterExp is an indicator of users with high financial capacity.

PrePVExp is seen to have a negative sign. Intuitively, it was thought that people with higher electricity costs, before having PV, would be more diligent to pay for the new type of system. Contrastingly, the negative sign can be attributed to the distribution structure of the PrePVExp data. Since most of the users have low PrePVExp, by using the maximum-likelihood principle, it was found likely that even users with low PrePVExp can still have good financial performance. We thus speculate that having a low PrePVExp can be expected from this rural community and this does not necessarily indicate poor financial performance. 
EasePay has a positive sign which indicates how users who find it easier to pay the costs of the SHS are more likely to perform well. EasePay here is considered to represent the willingness attribute of the user. By finding this component relevant, we find our first indication of the veracity of the capacity and willingness approach to sustainability as earlier discussed.

\section{Table 8 <Here>}

Source: author, from Survey and OLOGIT Analysis

Table 9 <Here $>$

Source: author, from Survey and OLOGIT Analysis

Fig. 5 a,b,c,d $<$ Here $>$

Source: author, from Survey and OLOGIT Analysis

By conducting a sensitivity analysis, we note the marginal effects $(d s / d x)$ of components and the changes in performance score probabilities as particular variable values change while holding all other values constant at their means. Results are seen in Fig. 5. While all variables are found to be significant, we take that TransExp has a range of values that is most significant to dictate the scores. The higher the TransExp the higher probability of poor performance. WaterExp and EasePay contribute positively to the probability of good performance and therefore are good indicators in further screen out good and poor performers.

\subsubsection{Model for 3-category Financial Performance}

The model developed for the 3-category financial performance ( $C_{-} 3 \_$Financial $)$is shown in Table 10. The model chi ${ }^{2}$ and pseudo- $\mathrm{R}^{2}$ were found acceptable with an overall prediction accuracy of $74 \%$, which was lower than the 2-category predictions. Results in Table 11 show correct predictions for 6 out of the 12 poor performers, 21 out of 23 average performers, and 8 out of 12 good performer. There were 5 significant variables retained: GrossIncome, $P \_$FoodExp, $P \_$TransExp, $P \_H e a l t h E x p$, and $P \_$WillMaxPay.

GrossIncome was found to have a positive coefficient, indicating how a user has the ability to earn money and have the necessary funds to pay for the SHS.

$P \_$FoodExp, $P \_$TransExp, and $P \_$HealthExp have negative coefficients. These values are percentages of users`expenses vs. GrossIncome. This confirms that household expenses may compete with costs or payment for the PV system and thus affect the ability 
of the user to pay. Hence, higher expenses, such as food, transportation, and health, relative to the gross income may indicate some challenges for SHS financial performance. Percentage values relative to GrossIncome allow us to relatively compare the performance trends for the low income and high income earners. These expense percentages can also be perceived as contributions of the external environment to the performance of users. If transportation and health facilities are, for example, difficult to access for a community, these percentages would be higher and may cause difficulties for users to pay for SHS. These components, as well as GrossIncome, altogether interact to represent the capacity component users.

$P_{-}$WillMaxPay is seen to have a positive coefficient, representing the willingness component of the user. As it is a percentage value to the GrossIncome, we are able to observe the willingness of users relative to their incomes. This relative sense of willingness may arguably be a better indicator of willingness than the actual willingness to pay value. The significance of $P_{-}$WillMaxPay to the model, nonetheless, confirms our hypothesis of being able to use both the capacity and willingness components to explain users` performance.

\section{Table $10<$ Here $>$}

Source: author, from Survey and OLOGIT Analysis

\section{Table $11<$ Here $>$}

Source: author, from Survey and OLOGIT Analysis

\section{Fig. 6 a,b,c,d,e <Here>}

Source: author, from Survey and OLOGIT Analysis

Sensitivity analysis was again conducted to determine the marginal effects and effects on probabilities of particular variables. Results are seen in Fig. 6. Among the three expense variables $\left(P_{-}\right.$FoodExp, $P_{-}$TransExp, and $P_{-}$HealthExp), only $P_{-}$FoodExp had the range of values which significantly dictates the scores from poor, to average, and to good performance. $P_{-}$WillMaxPay had negative marginal effect at the means and thus an increase in value would decrease the probability of poor performance.

\subsubsection{Technical Performance Estimation Using Ologit}

Applying ordered logit analysis, we are able to estimate the categorized A_Technical scores. The presented models for 2-category and 3-category were considered to be the 
most admissible models developed using the criteria and process described for Ologit.

\subsubsection{Model for 2-category Technical Performance}

The model developed for the 2-category technical performance (C_2_Technical) is shown in Table 12. The model chi ${ }^{2}$ and pseudo- $\mathrm{R}^{2}$ were found acceptable with an overall prediction accuracy of $89 \%$. Results in Table 13 show how 7 out of 11 poor performers and 35 out of the 36 good performers were correctly identified. There were 4 significant variables retained: GrossIncome, Education, SelfRating, and P_WillMaxPay.

GrossIncome was found to have a positive coefficient. In the earlier model, this was a capacity indicator for the user`s financial capacity. For this case, GrossIncome shows how a person`s financial abilities can extend to reflect the technical abilities a person has to operate and maintain the SHS.

Education was found to have a positive coefficient, indicating how having better education can point towards better technical performance. Since Education was not found significant for financial performance, it can be said that education plays a more important role in the technical performance of users.

SelfRating had a negative coefficient. The distribution structure of SelfRating and A_Technical was analyzed and it was found that higher technical scorers rated themselves low in terms of knowhow about the system. This may indicate a general trend of users perception and confidence about their knowledge of the system: those who are better educated may be more aware of the complexities of the system and thus rate themselves low. Those who perform poorly may have tendencies to rate themselves higher than what they may really know.

P_WillMaxPay was seen to have a positive coefficient. While this variable points to the financial willingness of the user, its significance in the technical model indicates how financial willingness can also reflect the willingness of users to maintain their systems. This confirms that willingness to pay is not only an amount to valuate a certain resource but also indicates the willingness component of users to sustain their systems. Further, this confirms how willingness plays an important role, along with other capacities, in operating and maintaining SHS.

Table $12<$ Here $>$

Source: author from Survey and OLOGIT Analysis

Table $13<$ Here $>$ 
Source: author, from Survey and OLOGIT Analysis

Sensitivity analysis was again conducted to determine the marginal effects and effects on probabilities of particular variables. Results are seen in Fig. 7. While all variables showed certain significance, particular attention should be given to GrossIncome and $P_{-}$WillMaxPay since these have a range of values that define poor and good performers. While Education also plays a significant role, care should be given for SelfRating as users` perception of their knowledge may be counter intuitive.

Fig. 7 a,b,c,d <Here>

Source: author, from Survey and OLOGIT Analysis

\subsubsection{Model for 3-category Technical Performance}

The model developed for the 3-category technical performance ( $C_{-} 3_{-}$Technical $)$is shown in Table14. The model chi $^{2}$ and pseudo- $\mathrm{R}^{2}$ were found acceptable with an overall prediction accuracy of $64 \%$, which was lower than the 2-category predictions. Results in Table 15 showed correct predictions for 6 out of 11 poor performers, 18 out of 21 average performers, and 6 out of 15 good performers. The low accuracy rating can be attributed to the difficulty of distinguishing average and good performers.

There were 4 significant variables retained: GrossIncome, Education, SelfRating, and $P_{-}$WillMaxPay. These variables were the same for the 2-category scoring. All variables retained their coefficient signs, which confirm the consistent significance of these variables in explaining technical performance.

\section{Table $14<$ Here $>$}

Source: author, from Survey and OLOGIT Analysis

\section{Table 15 <Here>}

Source: author, from Survey and OLOGIT Analysis

Fig. 8 a,b,c,d <Here>

Source: author, from Survey and OLOGIT Analysis

Sensitivity analysis was again conducted to determine the marginal effects and effects on probabilities of particular variables. Results are seen in Fig. 8. The variables 
displayed similar effects with the 2-category model.

5. Practical Implications to Policies and Projects

The models developed have proven to have significantly predicted user performance given household attributes typically found during RRAs. The findings of this investigation allow us to have policy and project implications for at least four fronts: (1) project beneficiary scoping, (2) appropriate technology selection, (3) capacity development strategies, and (4) willingness development strategies. These may be applied to both private and public development projects and processes.

Project beneficiary scoping refers to the initial selection of project beneficiaries from among many applicants who wish too be provided with these SHSs. The beneficiary selection process applied in Alumar granted systems to some users who were not fully capable of sustaining their systems. Through the models developed, it becomes possible to predict the performance tendencies of users and screen out those that are found incapable of sustaining the system. In selecting beneficiaries, developers may set certain threshold values for the significant capacity-related and willingness-related attributes of users.

Appropriate technology selection also takes place in the initial stages of the project where the type and sizing of the systems are designed to fit the users. By being able to infer user performance, developers can design systems that appropriately match users` capacities and needs. Taking the Alumar case, the poor performers, if predicted, could have been given alternative means of energy provision such as cheaper and smaller-sized SHS. Another alternative would have been rechargeable LED lamps (light emitting diode) which can be charged from the neighboring users` SHS, as proposed by [7].

Capacity development strategies could also be formulated based on these identified capacity-related and willingness-related attributes. For the financial aspect, since expenses were quite prominent indicators, it may be feasible to have workshops on accounting and financial planning to help users better manage household expenditures. Another strategy would be to improve key infrastructure in the community to lessen the costs of significant commodities such as transportation and health. In the light of user willingness, it may be practical to include willingness development programs as part of project development.

Aside from outlining the practical policy implications, this paper also seeks to inspire further research in the field of RES sustainability. While capacity and willingness were found relevant, it may be worthwhile to investigate the factors affecting these attributes. These may involve external and internal factors such as the norms, culture, and 
relationships of individuals and communities.

6. Conclusions and Recommendations

This paper investigated the capacity and willingness of users in sustaining RES for rural electrification. The proposed capacity and willingness approach discussed an adaptation to the paradigm shift from the traditional resources approach to the capabilities approach of human development. It was thought how typical user attributes would be able to represent the capacities and willingness of individuals and therein explain their performance in sustaining RES.

A solar home system (SHS) project in a rural island (Alumar, Philippines) was investigated. For this investigation, sustainability was explained by user performance in two aspects, namely, financial performance and technical performance. It was found how both performances were practical to measure, making them effective as sustainability indicators for rural electrification projects. User attributes, which are typically measurable during rapid rural appraisals (RRAs), were collected for SHS users in the island. These attributes were used to predict the financial and technical performance of users using ordered logit regression (Ologit).

The models developed showed good distinction of attributes that characterize a particular type of performance. Financial capacity attributes, i.e., income and expense, were prominent in explaining financial performance while technical knowhow-related attributes, e.g., education, were prominent in explaining technical performance. It was proven that willingness related attributes, i.e., willingness to pay, of users were influential in explaining both financial and technical performance.

The results of the investigation propose several practical policy and project implications: (1) project beneficiary selection process could be improved with the capability of predicting the performance of users; (2) the appropriate systems can be provided to match the estimated capacities of the users; (3) capacity development strategies can be developed to target significant capacity attributes, e.g., financial management, and environmental factors, e.g., transportation and health-related infrastructure, which affect user performance; (4) willingness development programs can be infused in existing training programs to provide better awareness of a person`s willingness in relation to the project.

Understanding sustainability has become more and more relevant as rural electrification projects progress to more unlit areas and communities. While RES sustainability remains elusively complex, developers may find it worthwhile to consider two important aspects, the users`capacity and willingness to sustain. 


\section{Acknowledgements}

The authors wish to acknowledge the cooperation of the following groups and individuals: the Global Center of Excellence (G-COE) Program of Tokyo Institute of Technology, the people and management of Barangay Alumar Power Association (BAPA), the staff of the Philippine Department of Energy - Visayas Energy Resource Development and Utilization Division (DOE-ERDUD), and the staff and supporters of Ruralenergy.org. The analyses and programs used in this research can be requested at www.ruralenergy.org website.

\section{References}

[1] World Bank. Designing Sustainable Off-Grid Rural Electrification Projects:

Principles and Practices. Washington DC : The World Bank, 2008.

[2] Chambers, R. Whose Reality Counts? Warwickshire UK : Practical Action Publishing, 2009.

[3] UNWCED, United Nations World Commission on Environment and Development. "Our Common Future". UK : Oxford, 1987.

[4] Lynam, J.K. and Herdt, R.W. Sense and Sustainability: Sustainability as an Objective in International Agricultural Research. s.1. : Agricultural Economics, 1989. pp. 381-398. Vol. 3.

[5] UNDP. Capacity Assessment Methodology: Users`s Guide. s.l.: United Nations Development Program, 2007.

[6] Hong, G.W. and Abe, N. Sustainability Assessment of Renewable Energy Projects for Off-Grid Rural Electrification: The Pangan-an Island Case in the Philippines. s.1.:

Renewable and Sustainable Energy Reviews, 2011, Vol. 16 (1) 54-64. doi: http://dx.doi.org/10.1016/j.rser.2011.07.136.

[7] Hong, G.W. and Abe, N. Modeling and Optimizing a Sub-Centralized LED Lamps Provision System for Rural Communities. s.l.: Renewable and Sustainable Energy Reviews, 2012, Vol. 16, pp. pp. 4616-4628. doi: http://dx.doi.org/10.1016/j.rser.2012.04.009.

[8] Hong, G.W., Abe, N. and Baclay, M. Else an Eventual Return to Conventional Energy: Impacts and Fate of an Off-Grid Rural Electrification Project in the Philippines. 4052-4056, s.1.: EU-PVSEC Proceedings, 2011. doi:10.4229/26thEUPVSEC2011-5DO.11.3. [9] NREL, National Renewable Energy Laboratory. Willingness to Pay for Electricity from Renewable Sources: A review of Utility Market Research. US: NREL, 1999. 
[10] Google. Google Maps. [Online] 2011. maps.google.com.

[11] Yonehara, A. Human Development Policy in the Global Era: A Proposal from an Educational View. s.l. : University Education Press, 2009.

[12] Alkire, S. The Capability Approach to the Quality of Life. [Online] 2008. http://www.stiglitz-sen-fitoussi.fr/documents/capability_approach.pdf.

[13] Sen, A.K. Inequality Reexamined. New York : Harvard University Press, 1992. [14] Sen, A.K. The Economics of Happiness and Capability. NY : Oxford University Press, 2008.

[15] Morgan, P. The Design and Use of Capacity Development Indicators. s.1. : Canadian International Development Agency, 1997.

[16] Todaro, M. and Smith, S. Economic Development. s.l. : Pearson Education Limited, 2009.

[17] USAID. S04 Strategy for Presenting and Reporting on NGO/CBO Capacity Building Activities: a concept paper and proposal presented at IWG meeting. 1998. [18] Browne, L., La Fond, A., and Macintyre, K. Measuring Capacity Building. [Online] 2001. http://www.heart-intl.net/HEART/Financial/comp/MeasuringCapacityBuilg.pdf.

[19] Stata Corp. Stata Statistical Software: Release 10. s.l.: StataCorp LP, 2007.

[20] Sambamoorthi, N. Hierarchical Cluster Analysis. [Online] 1999. http://www.crmportals.com/hierarchical_cluster_analysis.pdf.

[21] Tae, Y.J. Ordered Logit Model for Residential Electricity Demand in Korea. s.1. : Energy Economics, 1993.

[22] Armstrong, D. and Jackson, M. Ordered Logit and Probit. [Online] 2009. http://www.quantoid.net/ISS_week5_09.pdf.

[23] Hu, B., Shao, J., and Palta, M. Pseudo-R2 in Logistic Regression Model. 847-860, Wisconsin : Statistica Sinica, 2006, Vol. 16.

[24] Ayuso, M. and Santolino, M. Predicting Automobile Claims Bodily Injury Severity with Sequential Ordered Logit Models. s.l.: Mathematics and Economics, 2007, Vol. 41, pp. 71-83.

[25] Long, J.S. Regression Models for Categorical and Limited Dependent Variables. 1997. 


\section{Equations}

Eq. 1

$$
\operatorname{Pr}\left(y_{j}=i\right)=\operatorname{Pr}\left(k_{i-1}<S_{j}+u \leq k_{i}\right)
$$

Eq. 2

$$
S_{j}=x_{1 j} \beta_{1}+x_{2 j} \beta_{2}+\cdots+x_{m j} \beta_{m}
$$

Eq. 3

$$
\begin{gathered}
\operatorname{Pr}\left(S_{j}+u_{j}<k\right)=1 /\left(1+e^{S_{j}-k}\right) \\
\operatorname{Pr}\left(S_{j}+u_{j}>k\right)=1-1 /\left(1+e^{S_{j}-k}\right) \\
\operatorname{Pr}\left(k_{1}<S_{j}+u_{j}<k_{2}\right)=1 /\left(1+e^{S_{j}-k_{2}}\right)-1 /\left(1+e^{S_{j}-k_{1}}\right)
\end{gathered}
$$

\section{Figures}

Fig. 1: Photos of the Project and Solar Home System

Fig. 2: Model Development Process

Fig. 3: Capacity and Willingness Approach Framework

Fig. 4: User Attributes as Proxies for Capacity and Willingness

Fig. 5 (a,b,c,d): Sensitivity Analysis for $C_{-} 2$ _Financial

Fig. 6 (a,b,c,d,e): Sensitivity Analysis for $C_{-} 3 \_$Financial

Fig.7 (a,b,c,d): Sensitivity Analysis for C_2_Technical

Fig. 8 (a,b,c,d): Sensitivity Analysis for $C_{-}$3_Technical 


\section{Tables}

Table 1: Survey Data of User Attributes

Table 2: Technical Scoring Mechanics

Table 3: Categorizing User Attributes

Table 4: Categorical Scores for C_2_Financial

Table 5: Categorical Scores for C_3_Financial

Table 6: Categorical Scores for C_2_Technical

Table 7: Categorical Scores for C_3_Technical

Table 8: Model for C_2_Financial

Table 9: Model Predictions for $C \_2 \_F i n a n c i a l$

Table 10: Model for C_3_Financial

Table 11: Model Predictions for C_3_Financial

Table 12: Model for C_2_Technical

Table 13: Model Predictions for C_2_Technical

Table 14: Model for C_3_Technical

Table 15: Model Predictions for C_3_Technical 


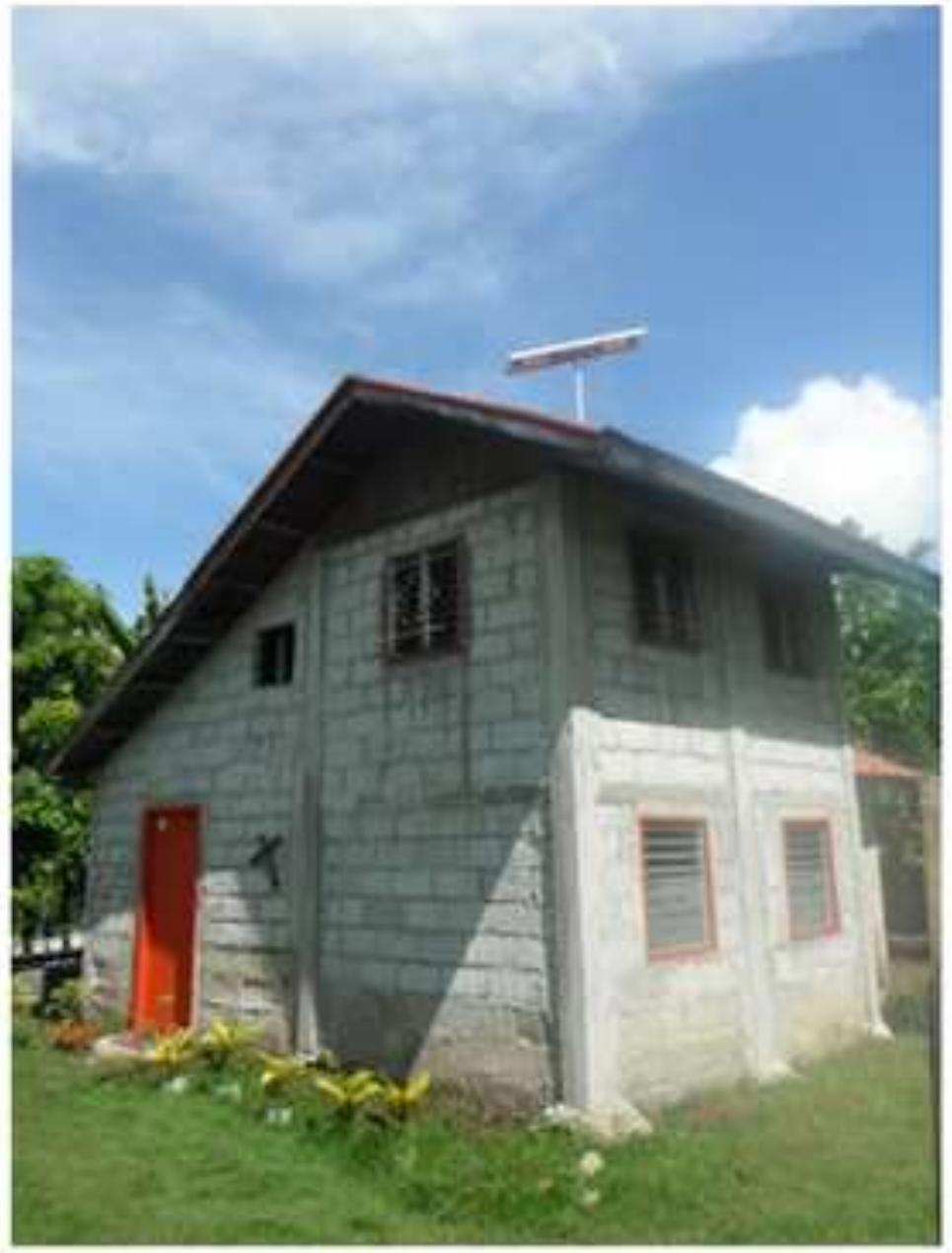

House with solar home system

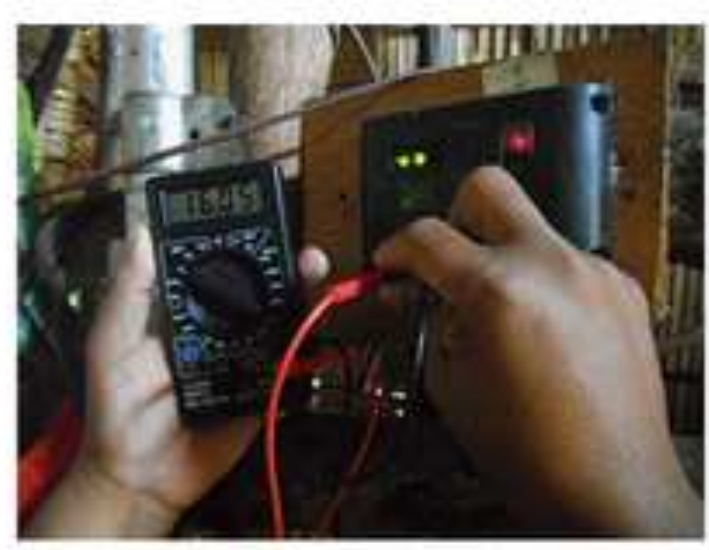

Charge controller

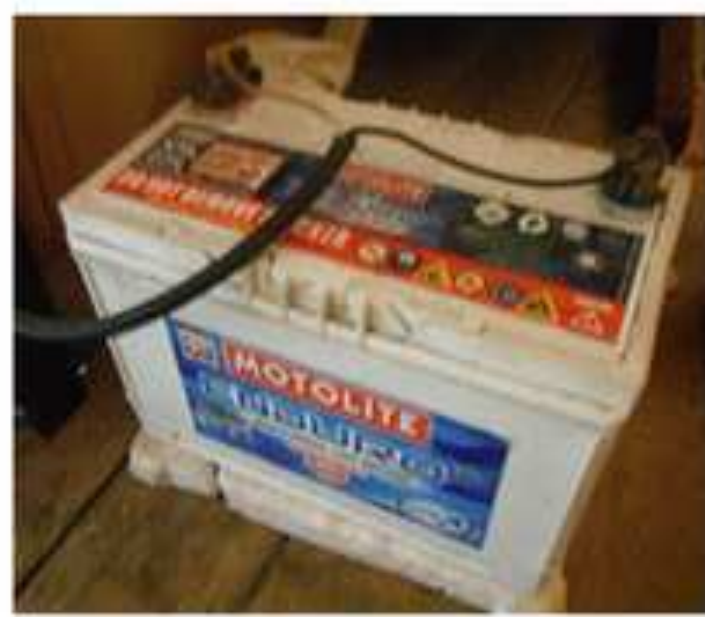

Lead-acid battery

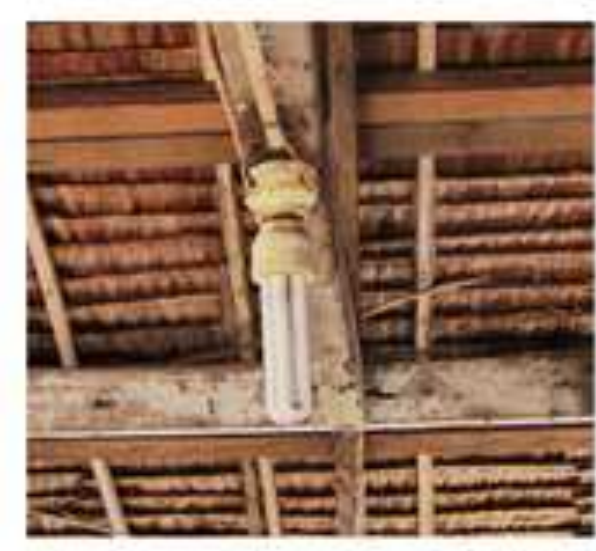

CFL

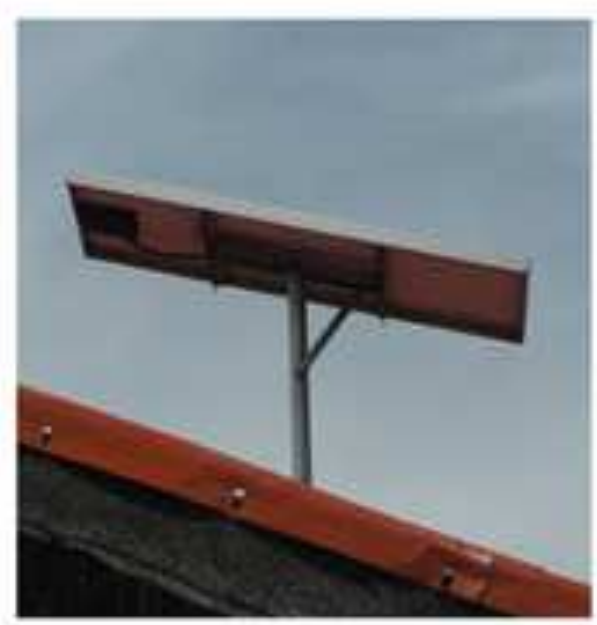

Solar panel ( 70 to $90 \mathrm{Wp})$ 
Step 1: Theoretical framework

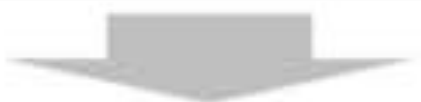

Step 2: Data collection / selection

Step 3: Variables classification

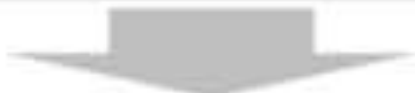

Step 4: Score categorization

Step 5: Model development

$$
\text { Step 6: Testing }
$$

- Definition of terms, model concept, and applicability to the case

- Check appropriateness and correctness of data

- Sort out variables related to capacity and willingness

- Scoring / Categorizing of data for indexing

- Ordered Logit models development and checking

- Testing the model predictability and sensitivity analysis 
Sustainability / Performance:

Financial and Technical

\section{Indicators / Proxies}

\section{Capacity and Willingness Approach}

User

capacity component

willingness component

Paradigm shift

Components considered

to determine sustainability performance distinct

component

\section{Traditional Resources Approach}

$$
\begin{aligned}
& \text { User } \\
& \text { PERFORMANCE }=\text { RESOURCES }( \\
& \text { User's income, consumption, } \\
& \text { access (electricity, water, health), ) } \\
& \text { Willingness to pay }
\end{aligned}
$$




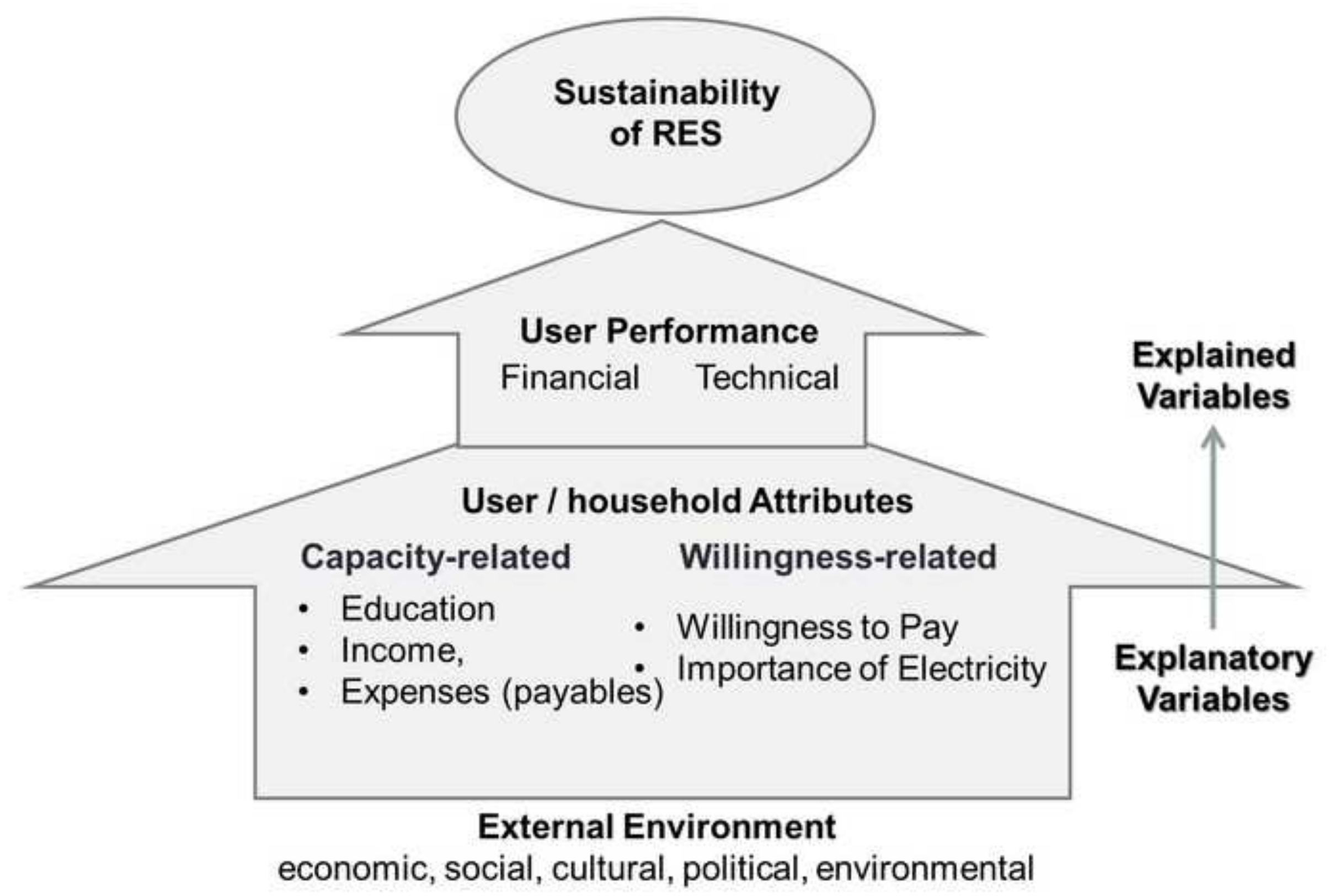




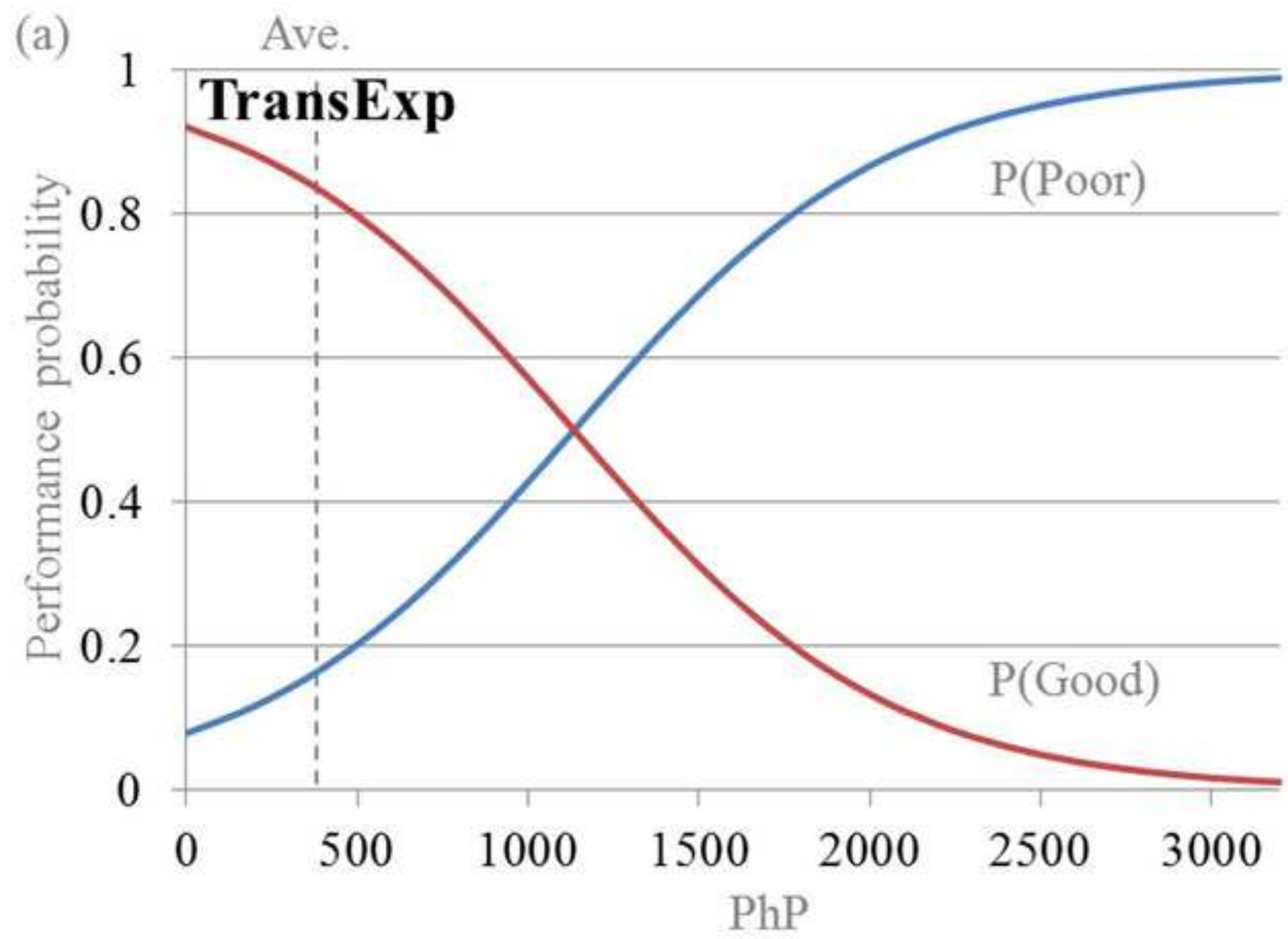




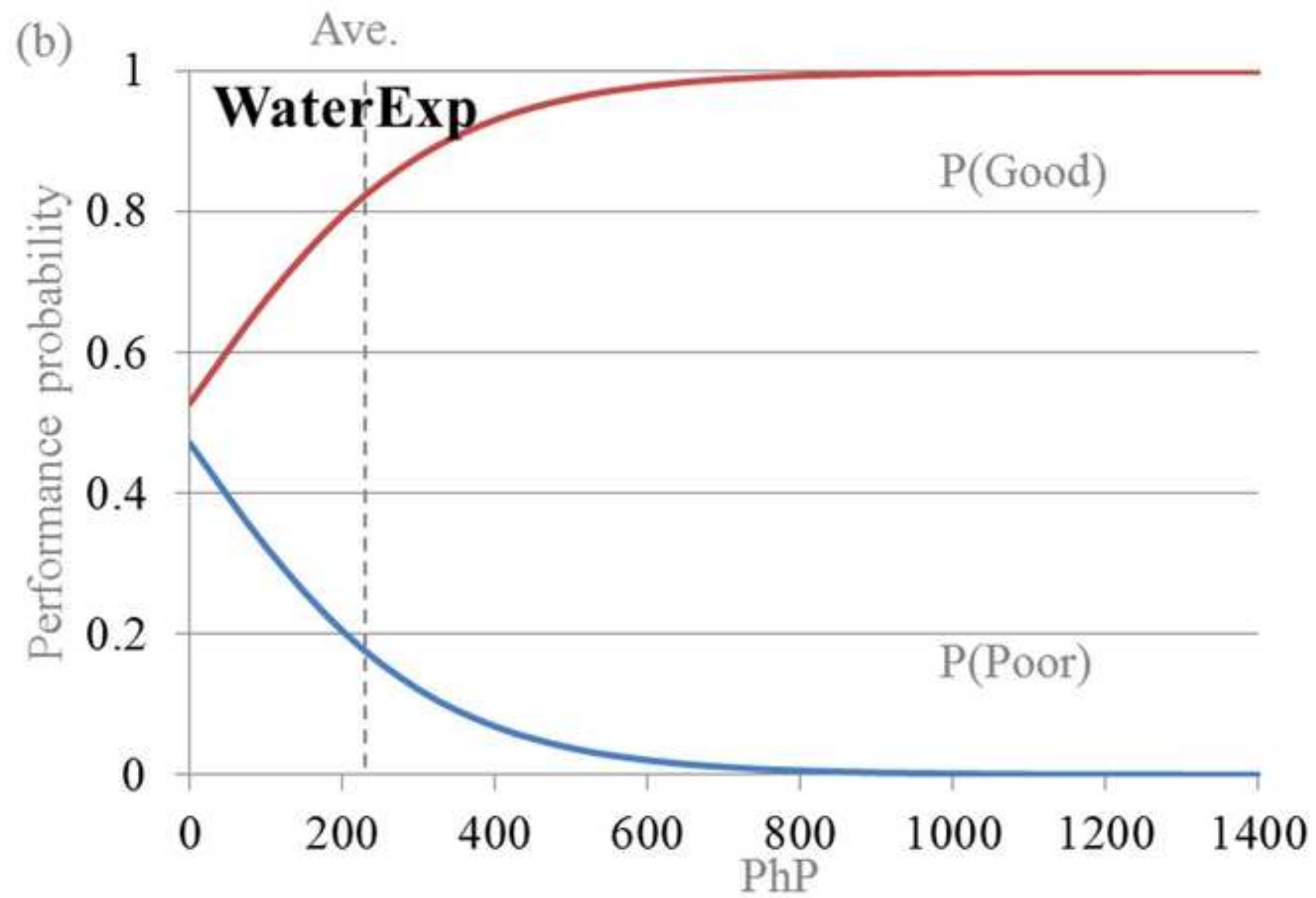




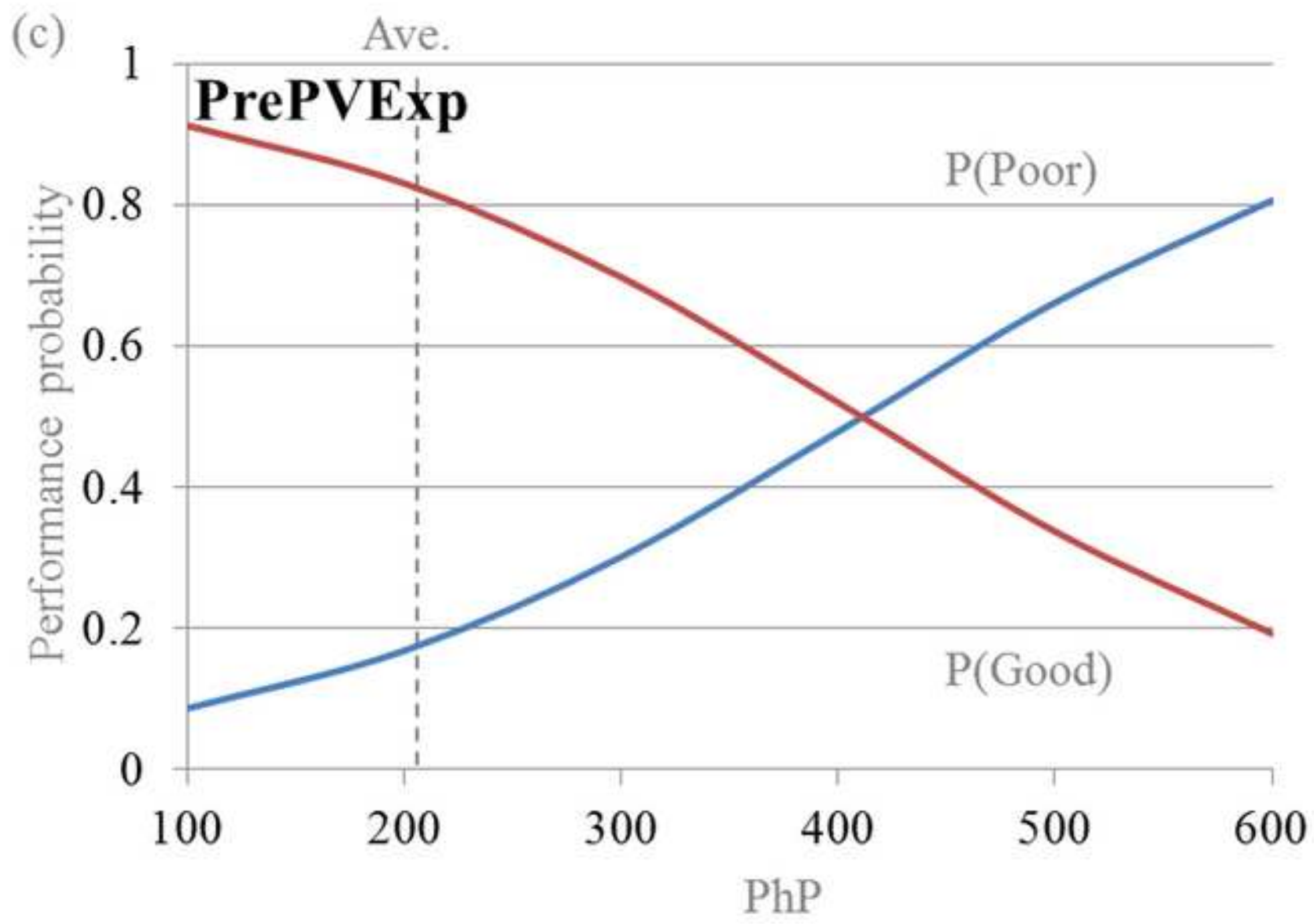




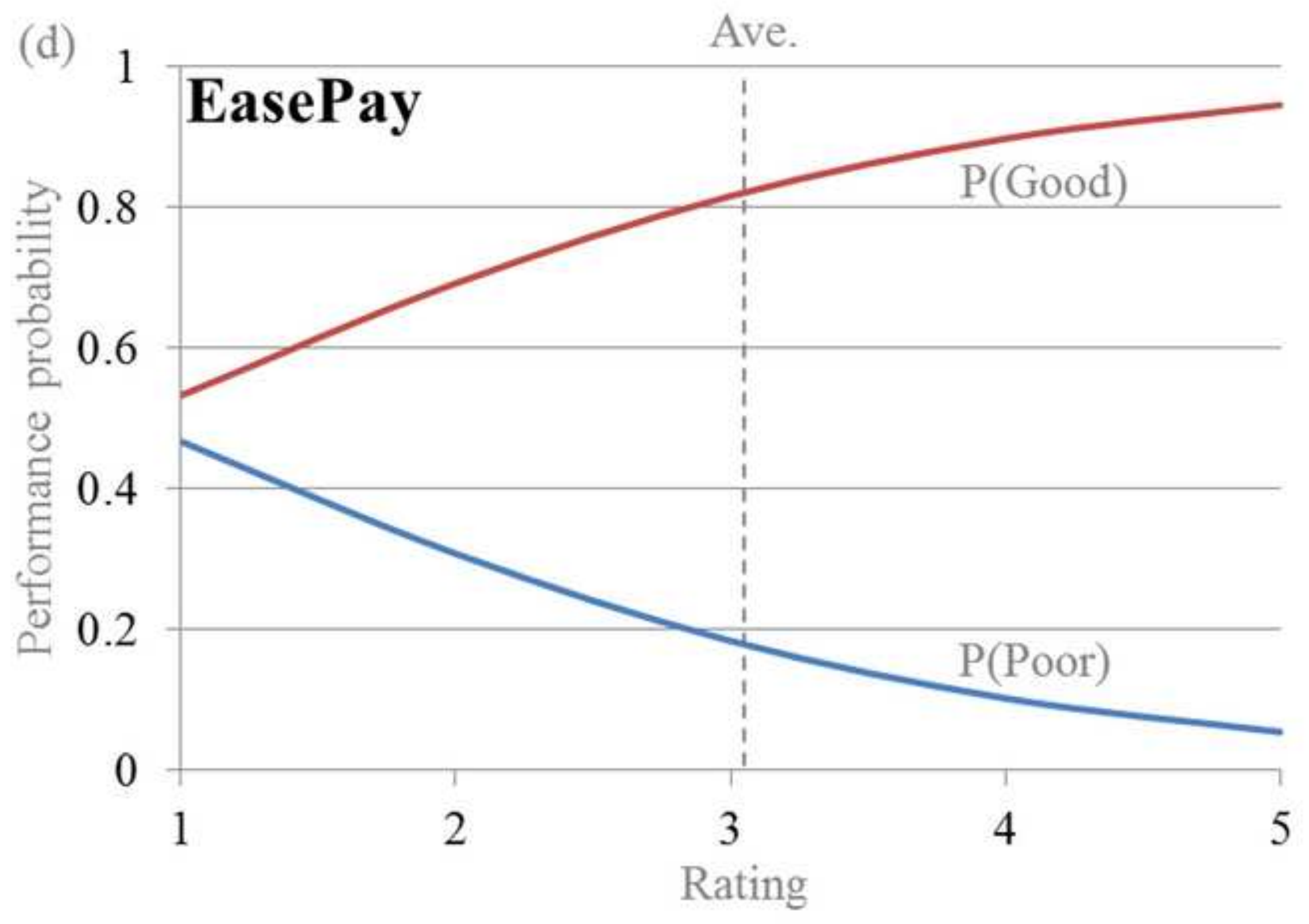



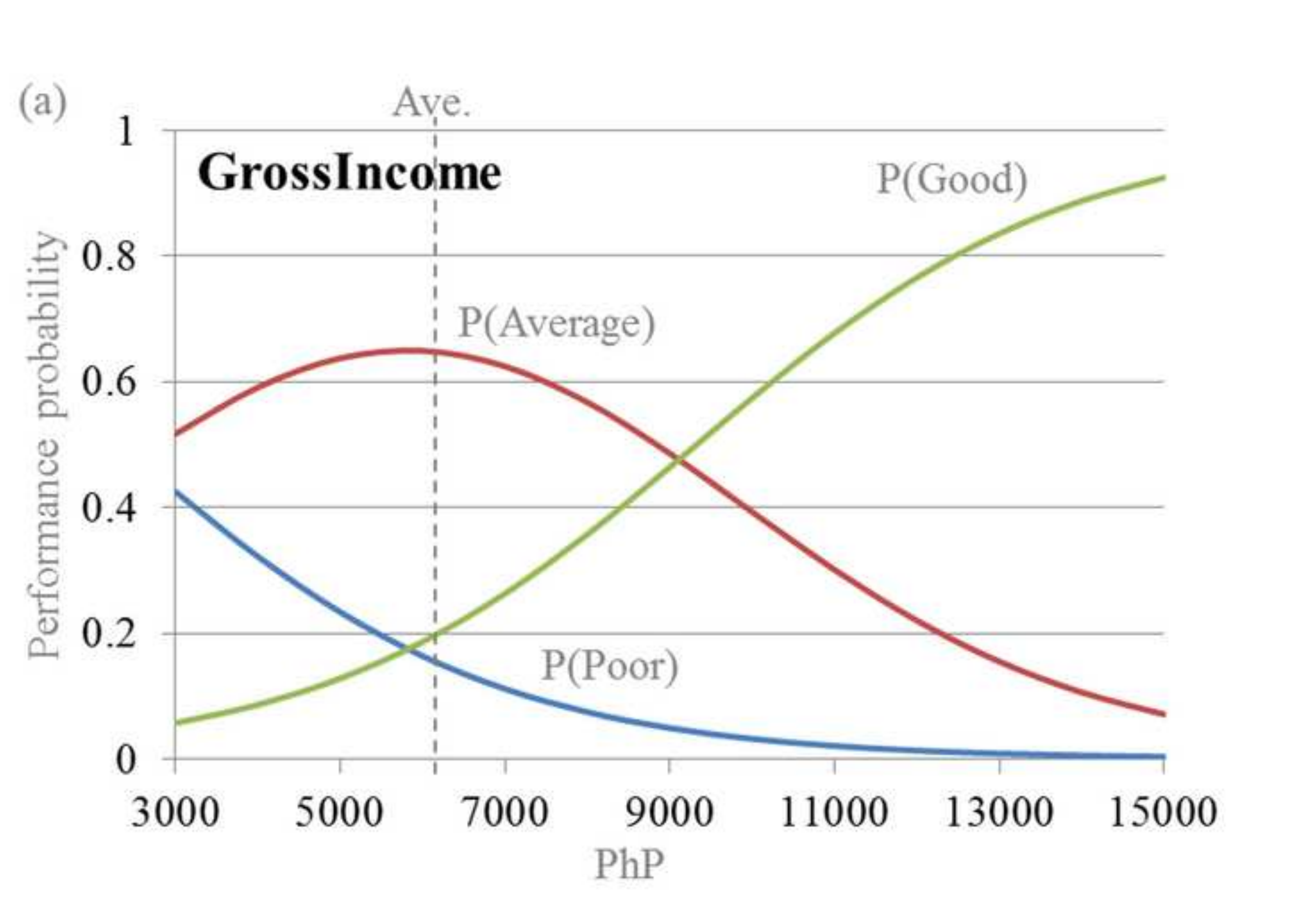


\section{Figure $6 \mathrm{~b}$}

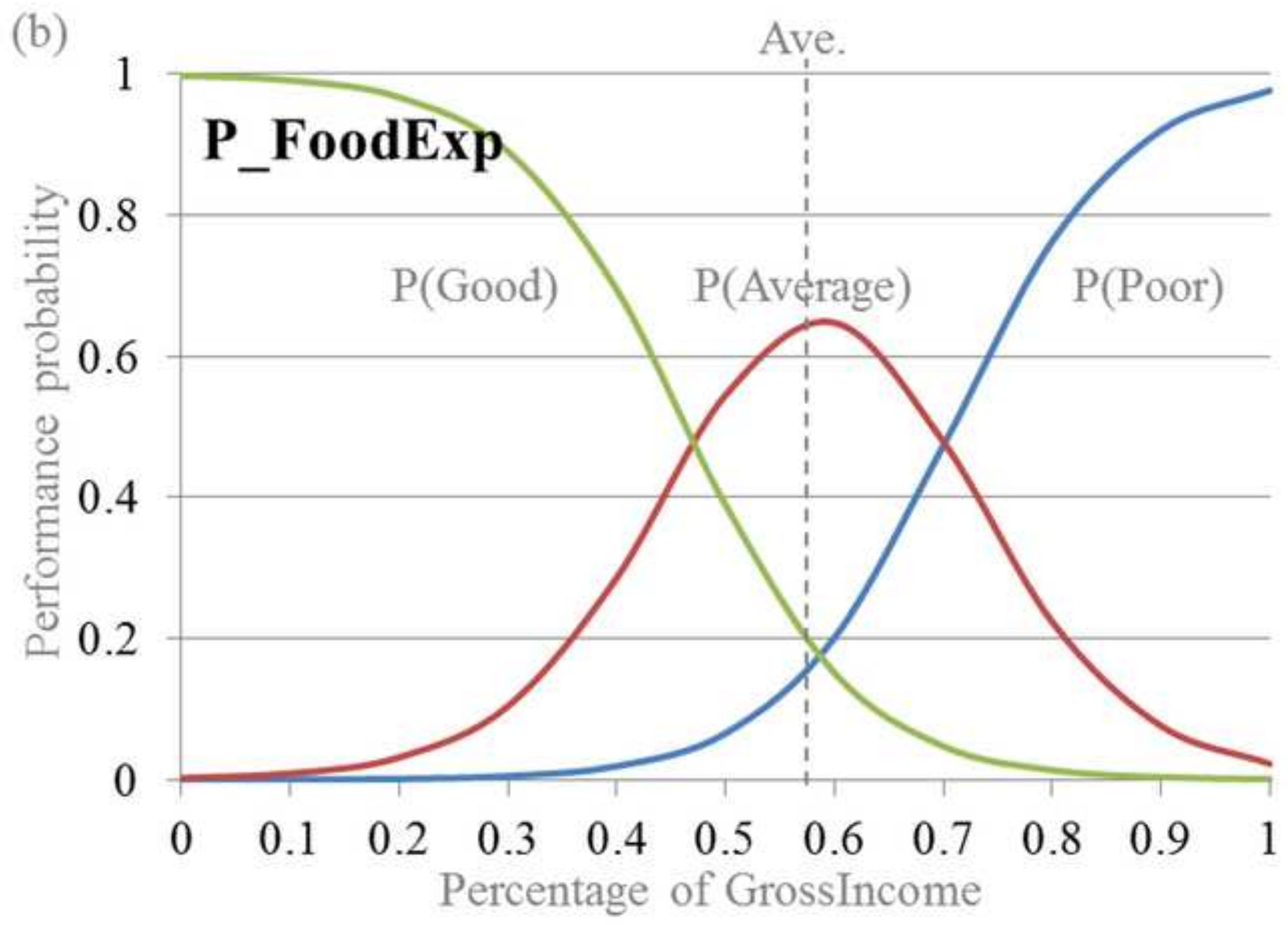


(d)

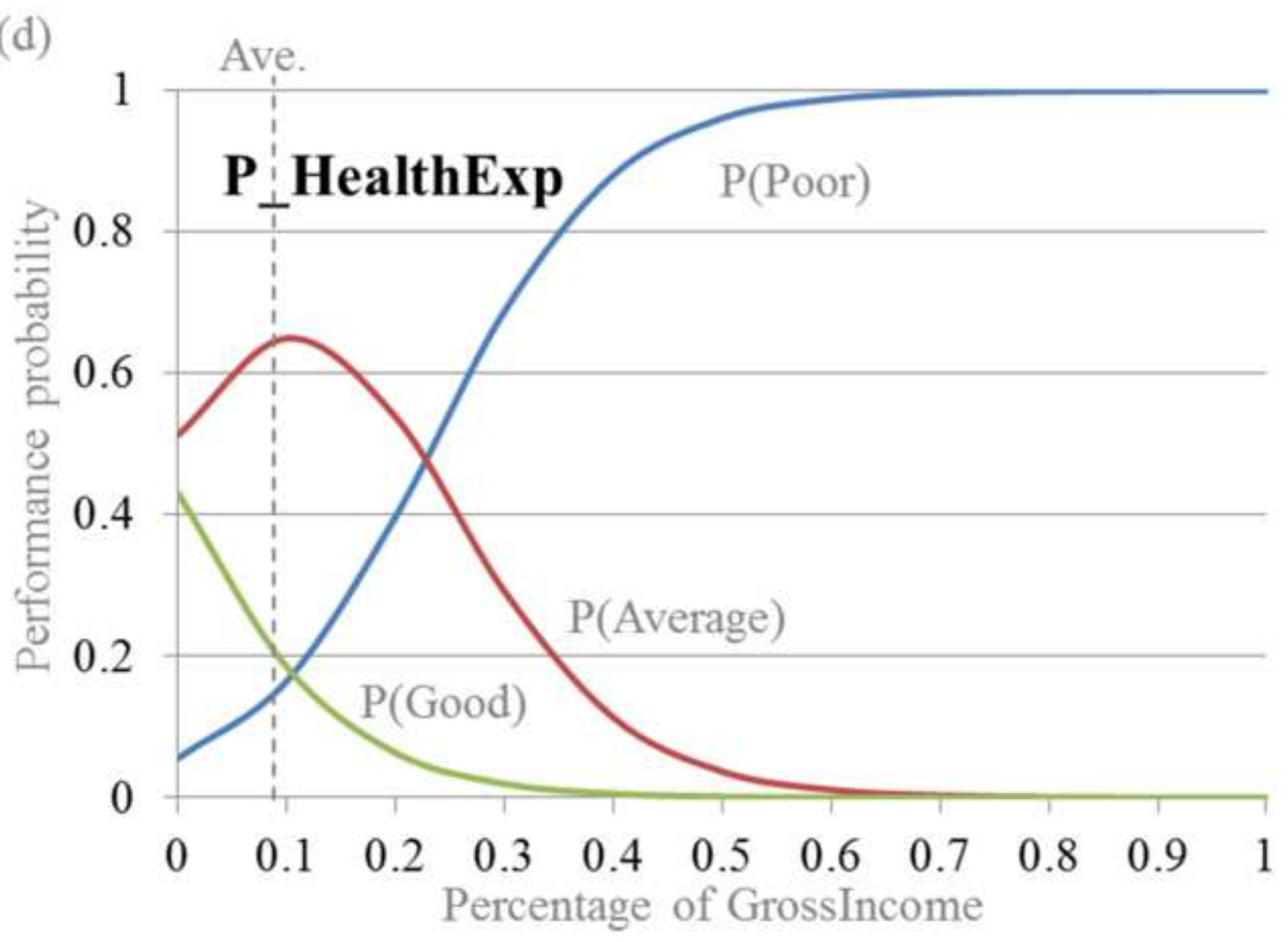




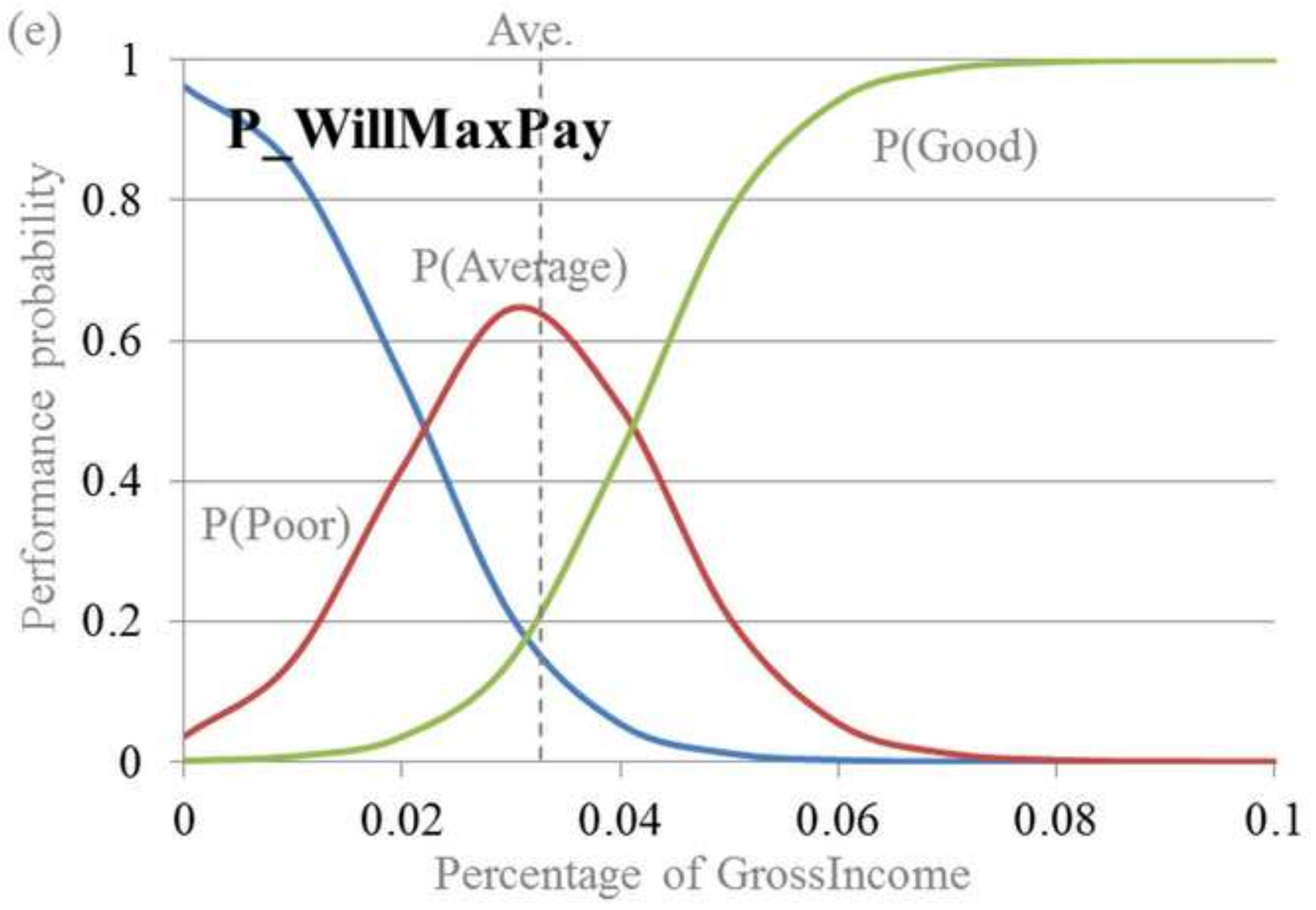




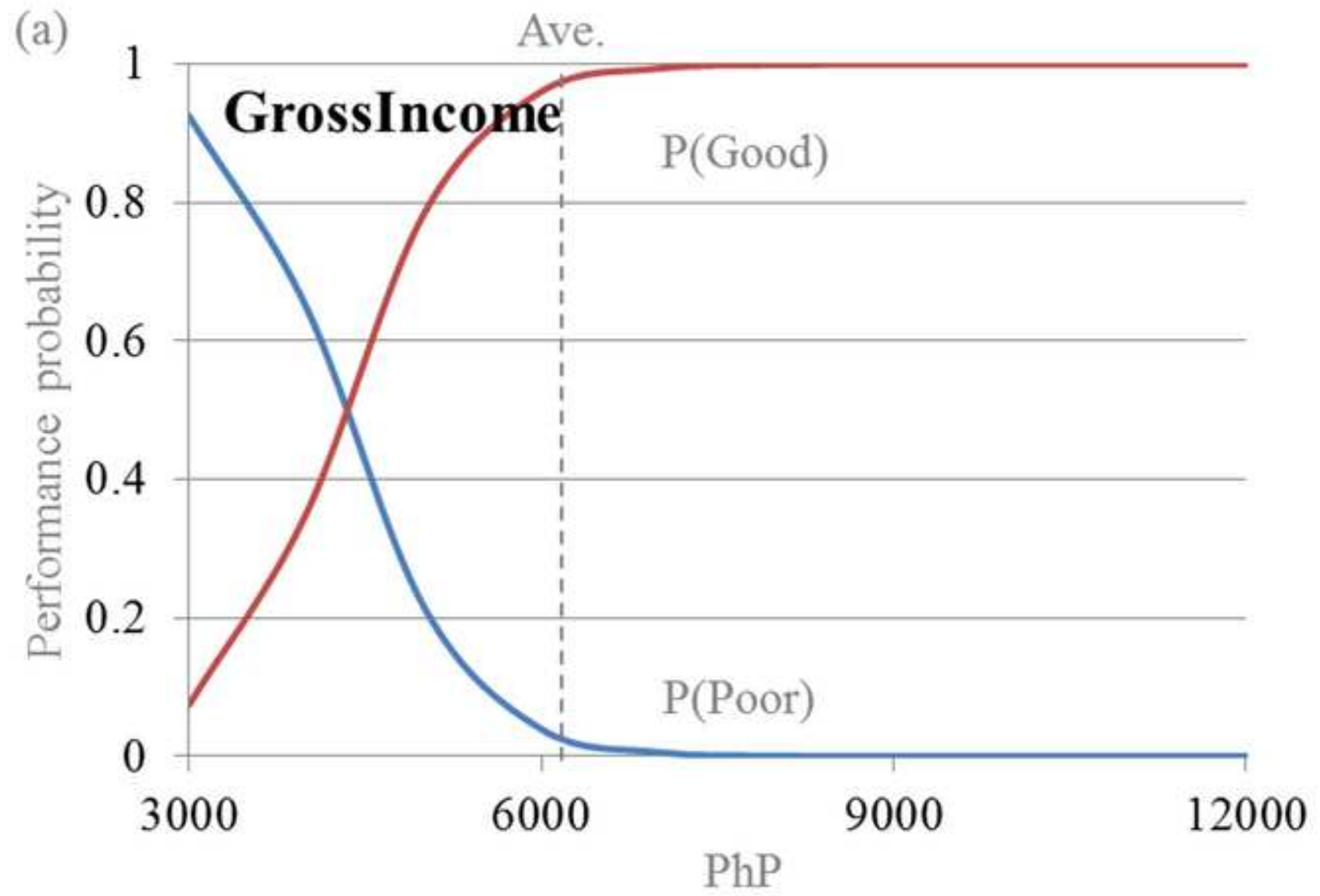




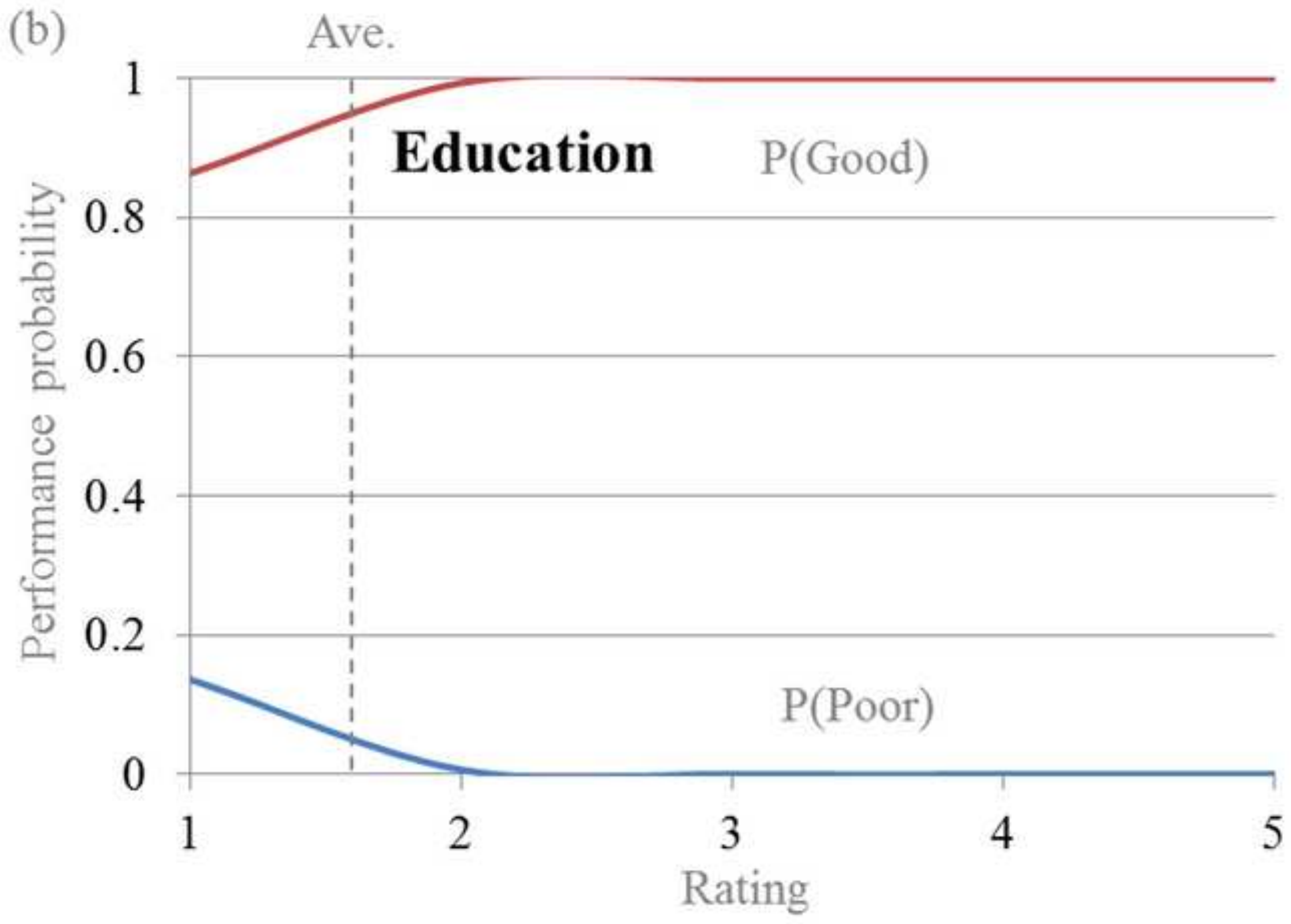




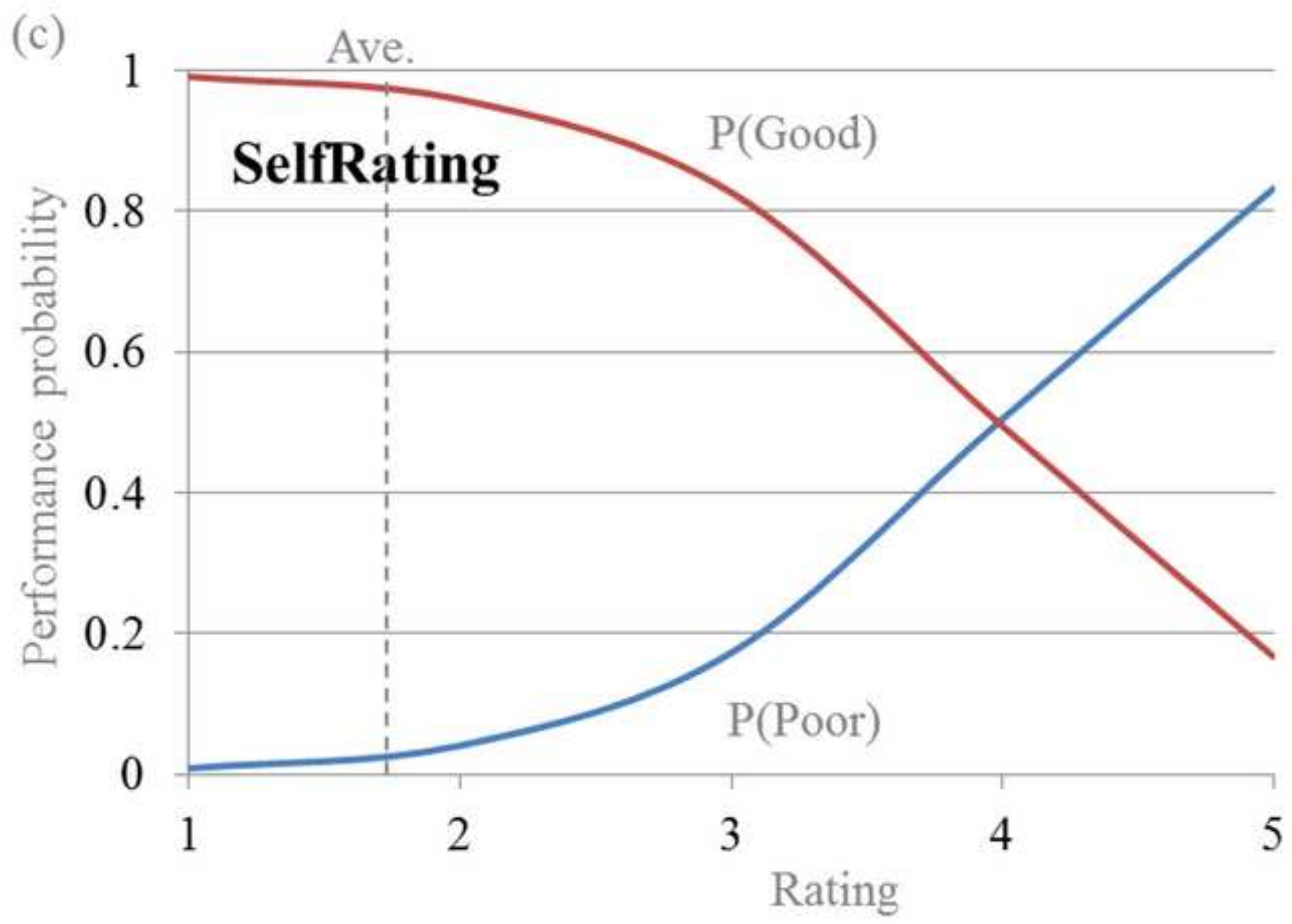




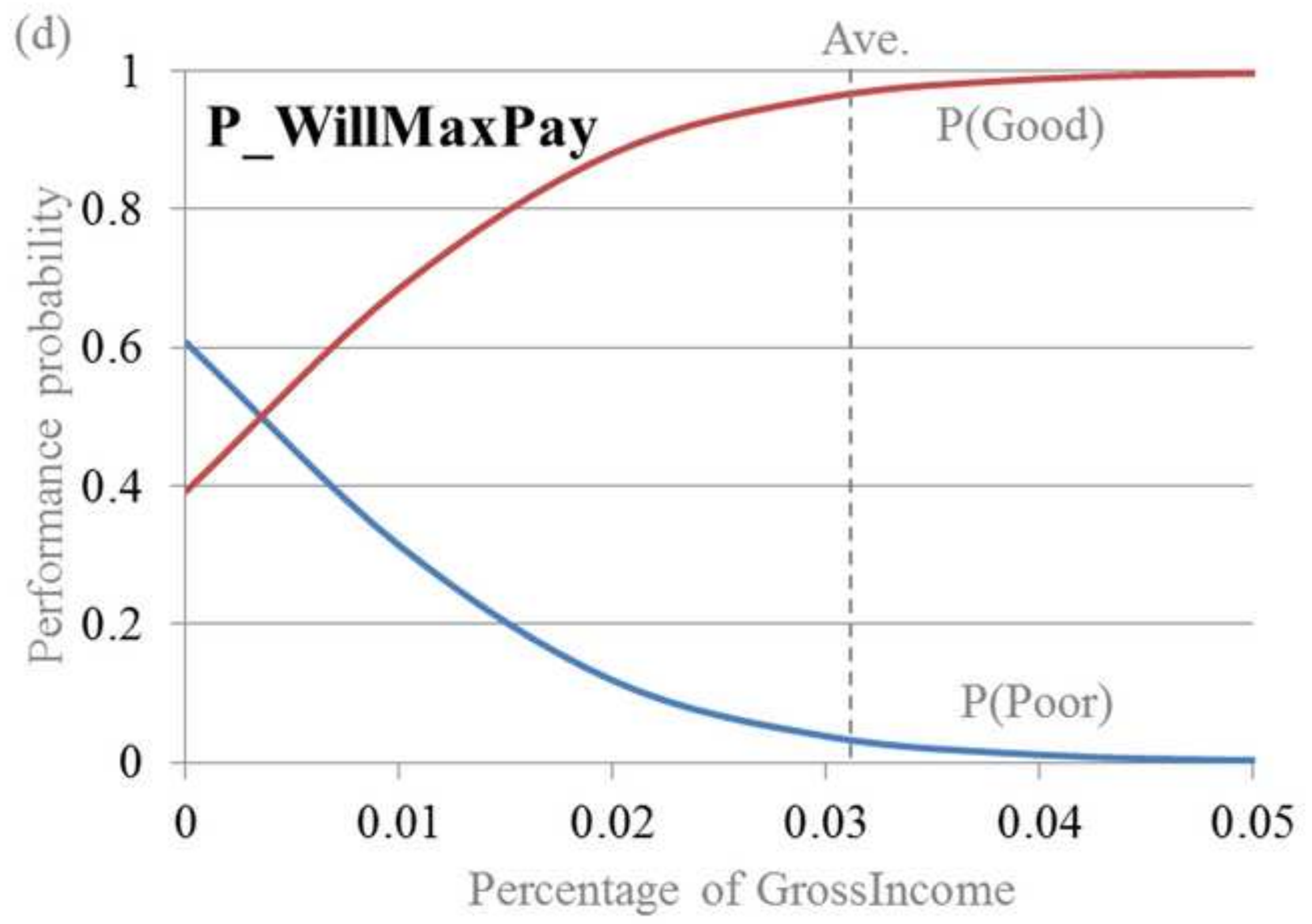




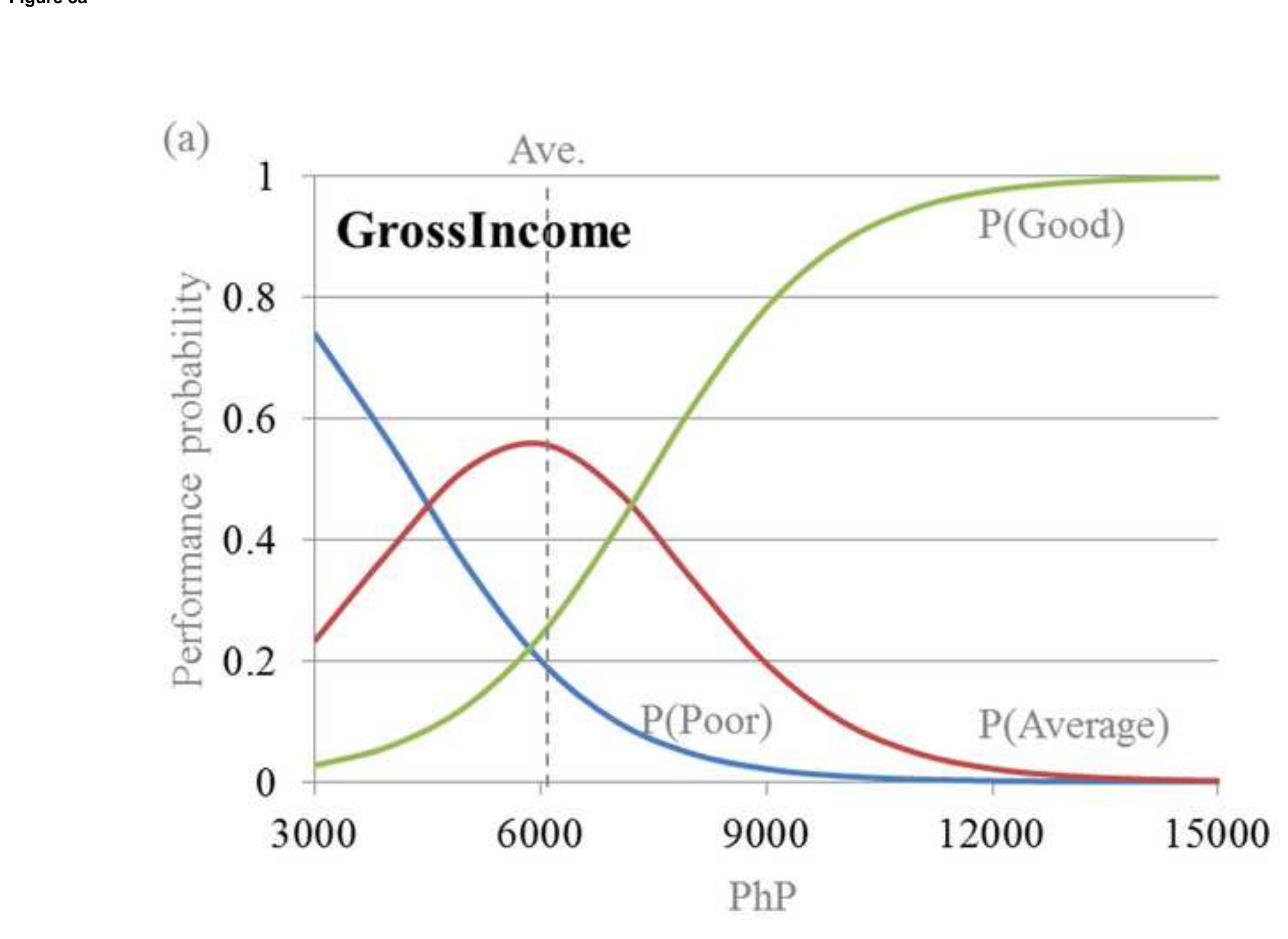

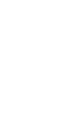

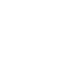
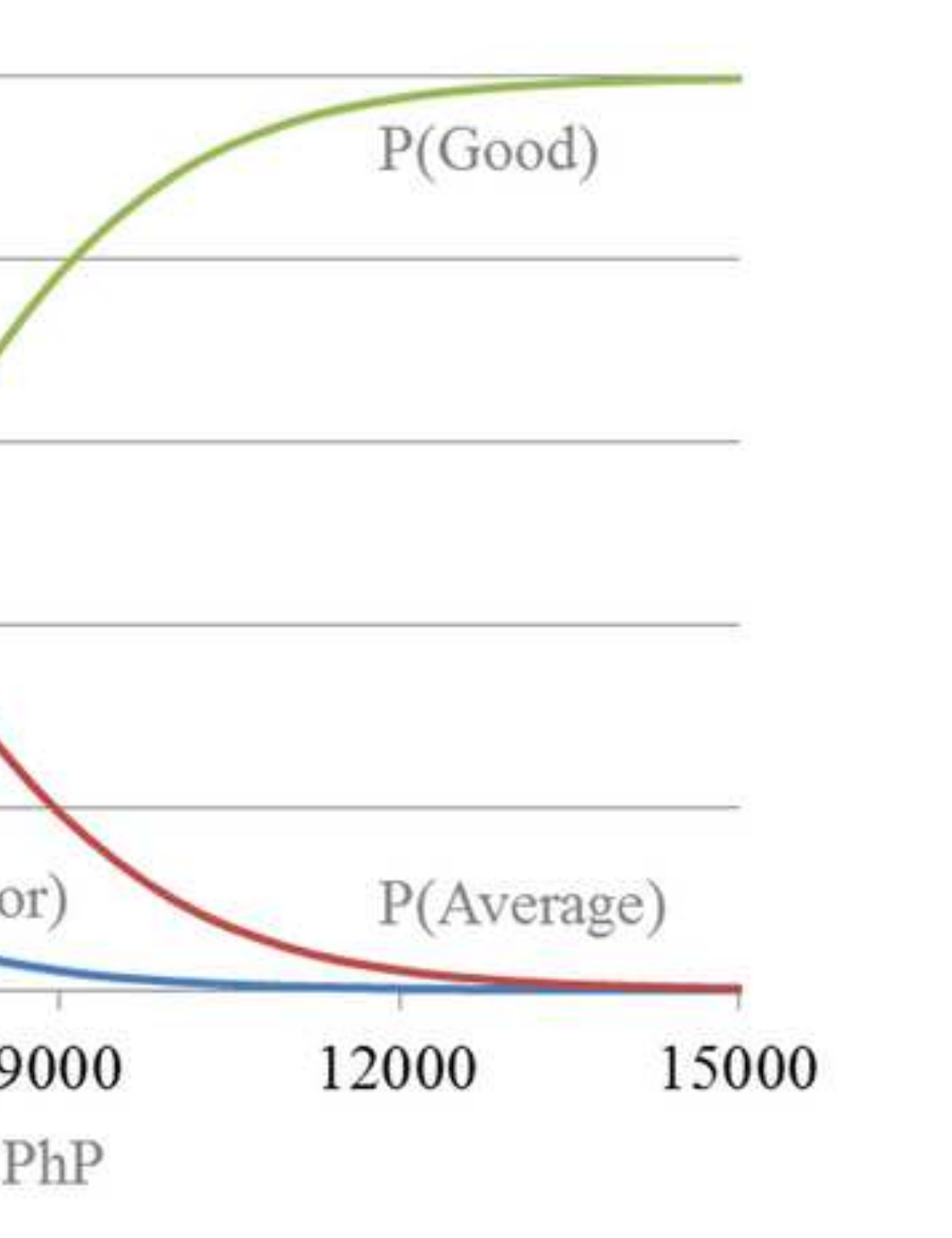

.

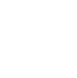


(c) Ave. SelfRating

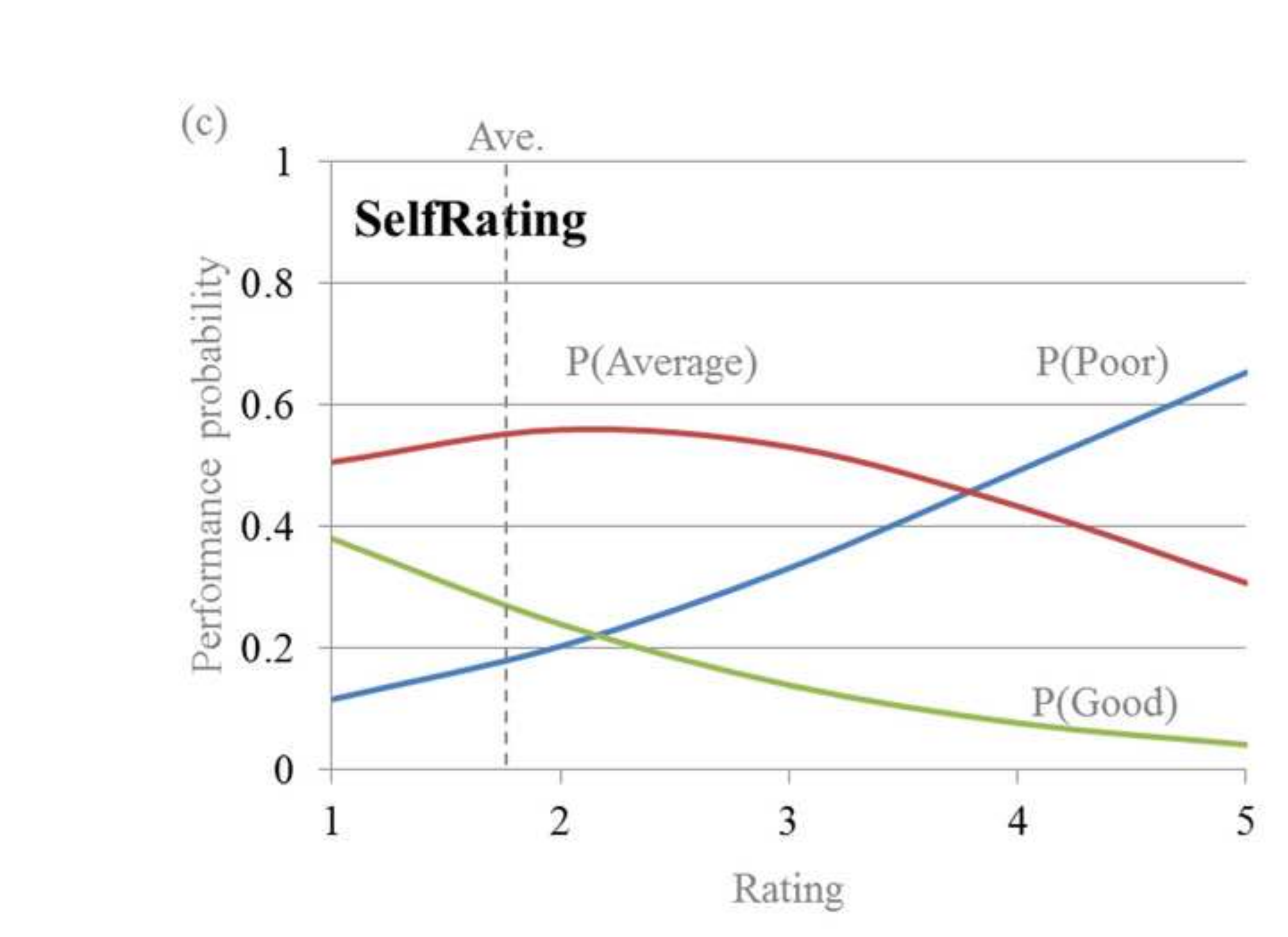

\section{(}
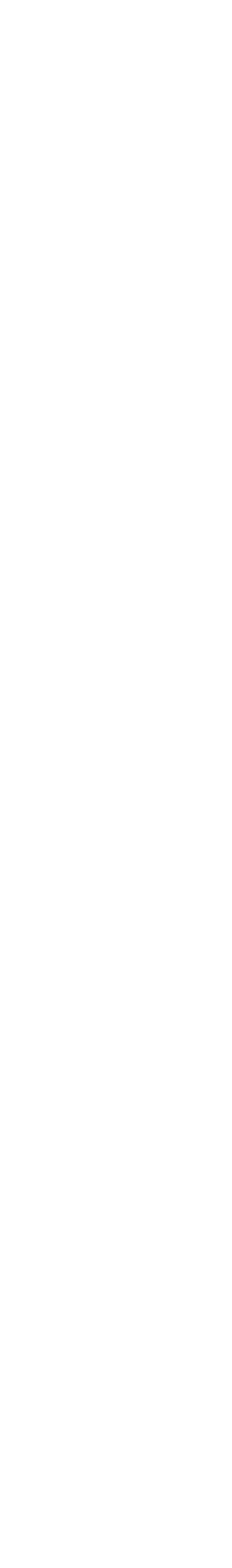

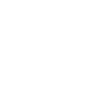
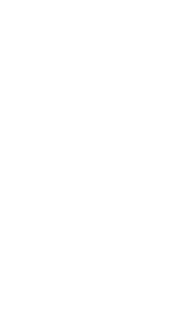
(d)

$$
1 \frac{\text { Ave. }}{1}
$$

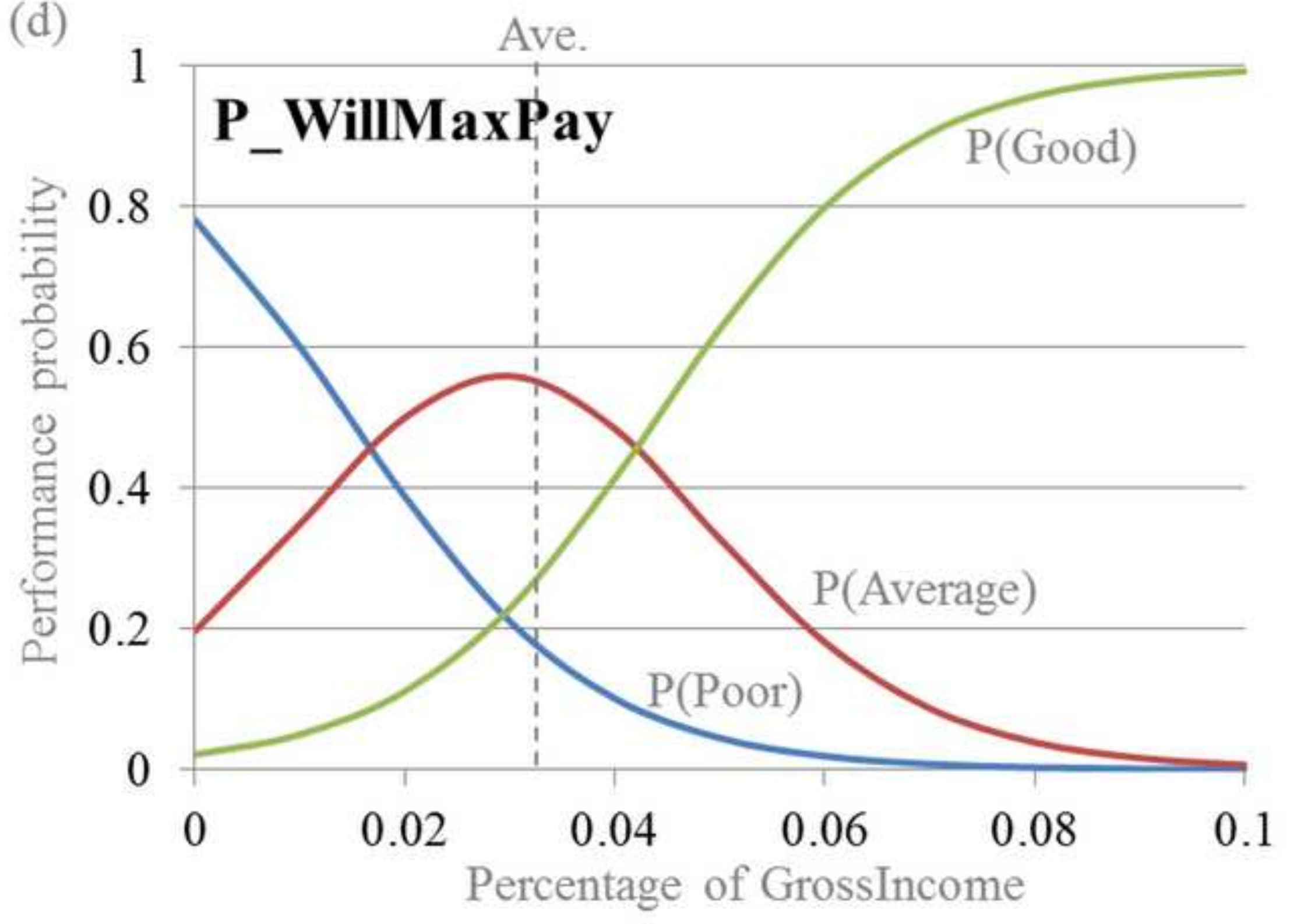

$\mathrm{P}$ (Good)

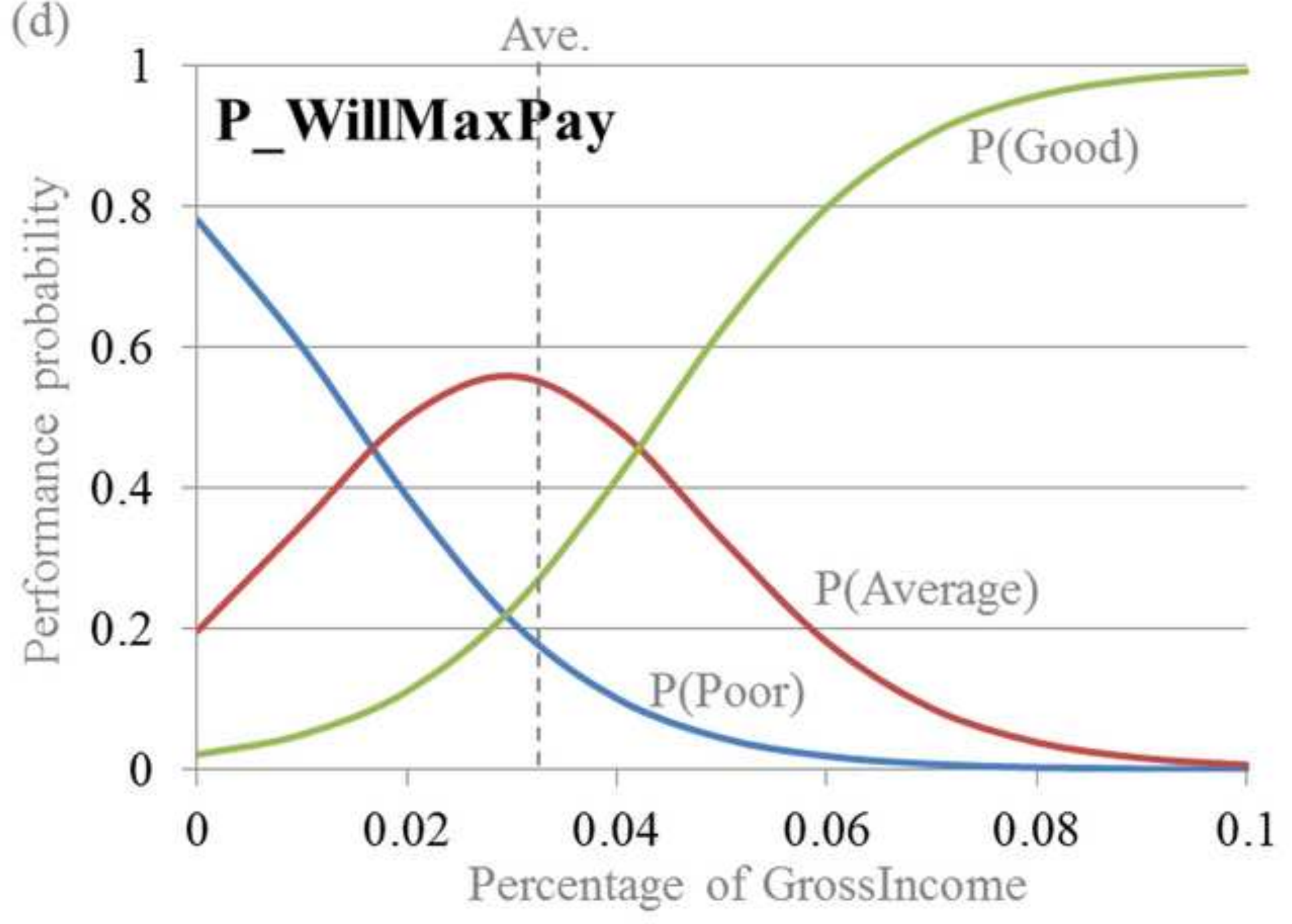

Percentage of GrossIncome 
Table 1: Survey Data of User Attributes

\begin{tabular}{|c|c|c|c|c|c|c|c|c|}
\hline & List of Variables & Var Name & Mean & StdDv. & Min & Max & Values & Units \\
\hline 1 & $\begin{array}{l}\text { Actual Financial } \\
\text { Performance }\end{array}$ & A_Financial & 0.70 & 0.2 & 0 & 1 & 0 to 1 & ratio \\
\hline 2 & $\begin{array}{l}\text { Actual Technical } \\
\text { Performance }\end{array}$ & A_Technical & 12.5 & 1.9 & 8 & 15 & $\begin{array}{l}\text { 0:low to } \\
\text { 15:high }\end{array}$ & Score \\
\hline 3 & Gross Income & GrossIncome & 6,172 & 2,321 & 3,000 & 15,000 & - & $\mathrm{PhP}$ \\
\hline 4 & Net Income & NetIncome & 687 & 701 & 20 & 4,400 & - & $\mathrm{PhP}$ \\
\hline 5 & Education & Education & 1.5 & 1.0 & 1 & 5 & $\begin{array}{l}\text { 1:low to } \\
\text { 5:high }\end{array}$ & score \\
\hline 6 & Age & Age & 44.9 & 10.2 & 25 & 63 & - & years \\
\hline 7 & Members & Members & 5.3 & 2.3 & 1 & 12 & - & persons \\
\hline 8 & Hours of Electricity use & ElecUse & 1.5 & 0.6 & 1 & 3 & $\begin{array}{l}\text { 1:low to } \\
\text { 3:high }\end{array}$ & score \\
\hline 9 & Food Expense & FoodExp & 3,461 & 1,353 & 1,000 & 9,200 & - & $\mathrm{PhP}$ \\
\hline 10 & Water Expense & WaterExp & 232 & 275 & 0 & 1,400 & - & $\mathrm{PhP}$ \\
\hline 11 & Education Expense & EducExp & 467 & 476 & 0 & 2,500 & - & $\mathrm{PhP}$ \\
\hline 12 & $\begin{array}{l}\text { Electricity Expense } \\
\text { (current) }\end{array}$ & ElecExp & 284 & 300 & 200 & 2,000 & - & $\mathrm{PhP}$ \\
\hline 13 & $\begin{array}{l}\text { Electricity Expense } \\
\text { (prior to PV system) }\end{array}$ & PrePVExp & 204 & 119 & 100 & 700 & - & $\mathrm{PhP}$ \\
\hline 14 & Health-related Expense & HealthExp & 570 & 503 & 100 & 2,500 & - & $\mathrm{PhP}$ \\
\hline 15 & Transportation Expense & TransExp & 412 & 489 & 0 & 3,120 & - & $\mathrm{PhP}$ \\
\hline 16 & $\begin{array}{l}\text { Self-rating of } \\
\text { system knowhow }\end{array}$ & SelfRating & 1.8 & 0.9 & 1 & 4 & $\begin{array}{l}\text { 1:low to } \\
\text { 5:high }\end{array}$ & score \\
\hline 17 & $\begin{array}{l}\text { Willingness to } \\
\text { Pay (Max) }\end{array}$ & Will_MaxPay & 184 & 38.1 & 70 & 250 & - & $\mathrm{PhP}$ \\
\hline 28 & Ease of Payment (SHS) & EasePay & 3.1 & 1.5 & 1 & 5 & $\begin{array}{l}\text { 1:low to } \\
\text { 5:high }\end{array}$ & score \\
\hline 19 & Willingness to Maintain & Will_Maintain & 4.9 & 0.4 & 4 & 5 & $\begin{array}{l}\text { 1:low to } \\
\text { 5:high }\end{array}$ & score \\
\hline 20 & Electricity Importance & ElecImp & 2.1 & 1.0 & 1 & 4 & $\begin{array}{l}\text { 1:low to } \\
5: \text { high }\end{array}$ & score \\
\hline
\end{tabular}

Source: Survey 2011b and Survey 2012 
Table 2: Technical Scoring Mechanics

\begin{tabular}{|c|c|c|c|c|}
\hline & Category & SCORING QUESTIONS & Score : Criteria & 15 pts. Total \\
\hline A. 1 & Battery & $\begin{array}{l}\text { How many times was the battery changed since } \\
2008 ?\end{array}$ & $\begin{array}{c}\text { 3: replaced }<=1 x \\
2: \text { replaced } 2 x \\
1: \text { replaced }>=3 x\end{array}$ & 3 \\
\hline A. 2 & & $\begin{array}{l}\text { Does the user have stocked distilled water supply } \\
\text { for the battery? }\end{array}$ & $\begin{array}{l}\text { 1: Yes } \\
0: \text { None }\end{array}$ & 1 \\
\hline A. 3 & & Is the battery clean (terminals and casing)? & $\begin{array}{l}\text { 1: Yes } \\
0: \text { No }\end{array}$ & 1 \\
\hline B.1 & $\begin{array}{l}\text { Charge } \\
\text { Controller }\end{array}$ & Is the charge controller clean (casing)? & $\begin{array}{l}\text { 2: Very clean } \\
\text { 1: Considerably } \\
\text { clean } \\
\text { 0: Not at all }\end{array}$ & 2 \\
\hline B. 2 & & $\begin{array}{l}\text { Is the charge controller positioned and connected } \\
\text { properly? }\end{array}$ & $\begin{array}{l}\text { 1: Yes } \\
0: \text { No }\end{array}$ & 1 \\
\hline B. 3 & & $\begin{array}{l}\text { Does the user bypass the controller } \\
\text { (even occasionally)? }\end{array}$ & $\begin{array}{l}\text { 2: Yes } \\
0: \text { No }\end{array}$ & 2 \\
\hline C. 1 & $\begin{array}{l}\text { Load, } \\
\text { Wiring, } \\
\text { and Usage }\end{array}$ & $\begin{array}{l}\text { Are the loads positioned properly } \\
\text { (e.g. lights, sockets)? }\end{array}$ & $\begin{array}{l}\text { 1: Yes } \\
0: \text { No }\end{array}$ & 1 \\
\hline C. 2 & & Are the loads wired properly? & $\begin{array}{l}\text { 1: Yes } \\
0: \text { No }\end{array}$ & 1 \\
\hline C. 3 & & Are the loads and wires clean? & $\begin{array}{l}\text { 1: Yes } \\
0: \text { No }\end{array}$ & 1 \\
\hline C. 4 & & Are there loads exceeding $12 \mathrm{~V} ?$ & $\begin{array}{l}\text { 1: Yes } \\
0: \text { No }\end{array}$ & 1 \\
\hline C. 5 & & $\begin{array}{l}\text { Are the loads used properly, not exceeding the } \\
\text { recommended loading time and amount? }\end{array}$ & $\begin{array}{l}\text { 1: Yes } \\
0: \text { No }\end{array}$ & 1 \\
\hline
\end{tabular}

Source: author, with expert opinion from DOE-VFO and BAPA staff 
Table 3: Classifying User Attributes

\begin{tabular}{|c|c|}
\hline \multicolumn{2}{|c|}{ Capacity-related } \\
\hline Financial attributes & Technical (know-how) attributes \\
\hline Gross income & Education \\
\hline Net income & Self-rating \\
\hline Expenses & Hours of electricity use \\
\hline \multicolumn{2}{|l|}{ Food } \\
\hline \multicolumn{2}{|l|}{ Water } \\
\hline Education & Other general attributes \\
\hline Electricity (prior to PV) & Members \\
\hline Electricity (current) & Age \\
\hline \multicolumn{2}{|l|}{ Health } \\
\hline \multicolumn{2}{|l|}{ Transportation } \\
\hline \multicolumn{2}{|c|}{ Willingness-related } \\
\hline Financial willingness & Technical willingness \\
\hline Willingness to pay (max) & Willingness to maintain (SHS) \\
\hline Ease of payment (SHS) & Electricity importance rating \\
\hline
\end{tabular}

Source: author 
Table 4: Categorical Scores for C_2_Financial

\begin{tabular}{ccccc}
\hline Score & Label & Range & Count & $\%$ \\
\hline Score 1 & Poor & $<0.55$ & 12 & $26 \%$ \\
Score 2 & Good & $>=0.55$ & 35 & $74 \%$ \\
& & Total & 47 & $100 \%$ \\
\hline
\end{tabular}

Source: author, from Survey 2011b, Survey 2012 and Cluster Analysis 
Table 5: Categorical Scores for C_3_Financial

\begin{tabular}{ccccc}
\hline Score & Label & Range & Count & $\%$ \\
\hline Score 1 & Poor & $<$ & 12 & $26 \%$ \\
Score 2 & Average & 0.55 & 23 & $49 \%$ \\
Score 3 & Good & 0.8 & 12 & $26 \%$ \\
& & Total & 47 & $100 \%$ \\
\hline
\end{tabular}

Source: author, from Survey 2011b, Survey 2012 and Cluster Analysis 
Table 6: Categorical Scores for C_2_Technical

\begin{tabular}{ccccc}
\hline Score & Label & Range & Count & $\%$ \\
\hline Score 1 & Poor & $<12$ & 11 & $23 \%$ \\
Score 2 & Good & $>=12$ & 36 & $77 \%$ \\
& & Total & 47 & $100 \%$ \\
\hline
\end{tabular}

Source: author, from Survey 2011b, Survey 2012 and Cluster Analysis 
Table 7: Categorical Scores for $C \_$___Technical

\begin{tabular}{ccccc}
\hline Score & Label & Range & Count & $\%$ \\
\hline Score 1 & Poor & $<12$ & 11 & $23 \%$ \\
Score 2 & Average & $12<=\mathrm{s}<14$ & 21 & $45 \%$ \\
Score 3 & Good & $>=14$ & 15 & $32 \%$ \\
& & Total & 47 & $100 \%$ \\
\hline
\end{tabular}

Source: author, from Survey 2011b, Survey 2012 and Cluster Analysis 
Table 8: Model for C_2_Financial

\begin{tabular}{|c|c|c|c|c|c|c|c|c|}
\hline Predictors & Coef. & Std.Err. & $\mathrm{z}$ & $\mathrm{P}>\mathrm{z}$ & [95\% Conf. & Interval] & $\mathrm{ds} / \mathrm{dx}$ & means \\
\hline TransExp & -0.0022 & 0.0013 & -1.71 & 0.087 & -0.0046 & 0.0003 & 0.0003 & 411.57 \\
\hline WaterExp & 0.0062 & 0.0028 & 2.20 & 0.028 & 0.0007 & 0.0118 & -0.0009 & 232.34 \\
\hline PrePVExp & -0.0076 & 0.0046 & -1.66 & 0.097 & -0.0165 & 0.0014 & 0.0011 & 204.06 \\
\hline EasePay & 0.6796 & 0.3203 & 2.12 & 0.034 & 0.0518 & 1.3074 & -0.0974 & 3.104 \\
\hline /cut1 & -0.4367 & 1.0770 & & & -2.5475 & 1.6741 & & \\
\hline \multicolumn{9}{|c|}{ [Prob > chi $\left.{ }^{2}: 0.0132\right]$ [Pseudo R $\left.{ }^{2}: 0.2368\right]$ [Prediction Accuracy: 85\%] } \\
\hline
\end{tabular}

Source: author, from Survey and OLOGIT Analysis 
Table 9: Model Predictions for C_2_Financial

\begin{tabular}{c|c|cc}
\hline Scores & Actual & \multicolumn{2}{|c}{ Predicted } \\
\hline Total & 47 & 7 & 40 \\
\hline 1 (Poor) & 12 & $6^{*}$ & 6 \\
2 (Good) & 35 & 1 & $34^{*}$ \\
\hline \multicolumn{2}{l}{ Note: $*$ Correctly predicted } & 1 (Poor) & 2 (Good) \\
\hline
\end{tabular}

Source: author, from Survey and OLOGIT Analysis 
Table 10: Model for $C \_3 \_F i n a n c i a l$

\begin{tabular}{|c|c|c|c|c|c|c|c|c|}
\hline Predictors & Coef. & Std.Err. & $\mathrm{z}$ & $\mathrm{P}>\mathrm{z}$ & [95\% Conf & Interval] & $\mathrm{ds} / \mathrm{dx}$ & means \\
\hline GrossIncome & 0.0004 & 0.0002 & 2.07 & 0.039 & 0.0000 & 0.0009 & -0.0001 & 6172.3 \\
\hline P_FoodExp & -12.72 & 3.75 & -3.40 & 0.001 & -20.06 & -5.38 & 1.65 & 0.57 \\
\hline P_TransExp & -17.05 & 8.97 & -1.90 & 0.057 & -34.62 & 0.52 & 2.22 & 0.06 \\
\hline P_HealthExp & -12.05 & 6.12 & -1.97 & 0.049 & -24.05 & -0.05 & 1.57 & 0.09 \\
\hline P_WillMaxPay & 152.05 & 53.72 & 2.83 & 0.005 & 46.76 & 257.34 & -19.77 & 0.03 \\
\hline /cut1 & -3.53 & 3.46 & & & -10.31 & 3.25 & & \\
\hline /cut2 & -0.43 & 3.40 & & & -7.09 & 6.23 & & \\
\hline \multicolumn{9}{|c|}{ [Prob > chi': 0.003] [Pseudo $\mathrm{R}^{2}: 0.2353$ ] [Prediction Accuracy: 74\%] } \\
\hline
\end{tabular}

Source: author, from Survey and OLOGIT Analysis 
Table 11: Model Predictions for C_3_Financial

\begin{tabular}{c|c|ccc}
\hline Scores & Actual & \multicolumn{3}{c}{ Predicted } \\
\hline Total & 47 & 7 & 30 & 10 \\
\hline 1 (Poor) & 12 & $6^{*}$ & 5 & 1 \\
2 (Ave) & 23 & 1 & $21^{*}$ & 1 \\
3 (Good) & 12 & 0 & 4 & $8^{*}$ \\
\hline \multicolumn{2}{l}{ Note: $*$ Correctly predicted } & 1 (Poor) & 2 (Ave) & 3 (Good) \\
\hline
\end{tabular}

Source: author, from Survey and OLOGIT Analysis 
Table 12: Model for $C \_2 \_T e c h n i c a l$

\begin{tabular}{ccccccccc}
\hline Predictors & Coef. & Std.Err & $\mathrm{z}$ & $\mathrm{P}>\mathrm{z}$ & {$[95 \%$ Conf.Interval] } & $\mathrm{ds} / \mathrm{dx}$ & means \\
\hline GrossIncome & 0.0019 & 0.0007 & 2.73 & 0.006 & 0.0005 & 0.0033 & -0.0001 & 6172.34 \\
Education & 3.14 & 1.69 & 1.86 & 0.063 & -0.17 & 6.45 & -0.088 & 1.532 \\
SelfRating & -1.58 & 0.79 & -2.01 & 0.044 & -3.13 & -0.042 & 0.044 & 1.766 \\
P_WillMaxPay & 122.05 & 66.27 & 1.84 & 0.065 & -7.83 & 251.94 & -3.42 & 0.0324 \\
\hline /cut1 & 14.19 & 6.19 & \multicolumn{7}{c}{2.06} & 26.32 \\
\hline
\end{tabular}

Source: author, from Survey and OLOGIT Analysis 
Table 13: Model Predictions for C_2_Technical

\begin{tabular}{c|c|cc}
\hline Scores & Actual & \multicolumn{2}{|c}{ Predicted } \\
\hline Total & 47 & 8 & 39 \\
\hline 1 (Poor) & 11 & $7 *$ & 4 \\
2 (Good) & 36 & 1 & $35^{*}$ \\
\hline \multicolumn{2}{l}{ Note: $*$ Correctly predicted } & 1 (Poor) & 2 (Good) \\
\hline
\end{tabular}

Source: author, from Survey and OLOGIT Analysis 
Table 14: Model for C_3_Technical

\begin{tabular}{|c|c|c|c|c|c|c|c|c|}
\hline Predictors & Coef. & Std.Err. & $\mathrm{z}$ & $\mathrm{P}>\mathrm{z}$ & \multicolumn{2}{|c|}{ [95\% Conf.Interval] } & $\mathrm{ds} / \mathrm{dx}$ & means \\
\hline GrossIncome & 0.0008 & 0.0003 & 3.1 & 0.002 & 0.0003 & 0.0013 & -0.0001 & 6172.34 \\
\hline Education & 0.63 & 0.32 & 1.96 & 0.05 & -0.0004 & 1.26 & -0.092 & 1.53 \\
\hline SelfRating & -0.67 & 0.38 & -1.75 & 0.08 & -1.42 & 0.08 & 0.098 & 1.77 \\
\hline P_WillMaxPay & 86.38 & 45.96 & 1.88 & 0.06 & -3.71 & 176.46 & -12.66 & 0.032 \\
\hline /cut1 & 6.05 & 2.81 & & & 0.54 & 11.56 & & \\
\hline /cut2 & 8.58 & 2.96 & & & 2.79 & 14.38 & & \\
\hline & rob $>c$ & 0.0021 & seud & $2^{2}: 0.16$ & [Predictio & Accuracy & 4\%] & \\
\hline
\end{tabular}

Source: author, from Survey and OLOGIT Analysis 
Table 15: Model Predictions for C_3_Technical

\begin{tabular}{c|c|ccc}
\hline Scores & Actual & \multicolumn{3}{|c}{ Predicted } \\
\hline Total & 47 & 7 & 31 & 9 \\
\hline 1 (Poor) & 11 & $6^{*}$ & 5 & 0 \\
2 (Ave) & 21 & 0 & $18^{*}$ & 3 \\
3 (Good) & 15 & 1 & 8 & $6^{*}$ \\
\hline Note: $*$ Correctly predicted & 1 (Poor) & 2 (Ave) & 3 (Good) \\
\hline
\end{tabular}

Source: author, from Survey and OLOGIT Analysis 